\title{
A mass conservative and water storage consistent variable parameter Muskingum-Cunge approach
}

\author{
E. Todini \\ Department of Earth and Geo-Environmental Sciences, University of Bologna, Italy
}

Received: 23 May 2007 - Published in Hydrol. Earth Syst. Sci. Discuss.: 12 June 2007

Revised: 11 September 2007 - Accepted: 1 October 2007 - Published: 15 October 2007

\begin{abstract}
The variable parameter Muskingum-Cunge (MC) flood routing approach, together with several variants proposed in the literature, does not fully preserve the mass balance, particularly when dealing with very mild slopes $\left(<10^{-3}\right)$. This paper revisits the derivation of the MC and demonstrates (i) that the loss of mass balance in $\mathrm{MC}$ is caused by the use of time variant parameters which violate the implicit assumption embedded in the original derivation of the Muskingum scheme, which implies constant parameters and at the same time (ii) that the parameters estimated by means of the Cunge approach violate the two basic equations of the Muskingum formulation. The paper also derives the modifications needed to allow the MC to fully preserve the mass balance and, at the same time, to comply with the original Muskingum formulation in terms of water storage. The properties of the proposed algorithm have been assessed by varying the cross section, the slope, the roughness, the space and the time integration steps. The results of all the tests also show that the new algorithm is always mass conservative. Finally, it is also shown that the proposed approach closely approaches the full de Saint Venant equation solution, both in terms of water levels and discharge, when the parabolic approximation holds.
\end{abstract}

\section{Introduction}

In 1938 McCarthy $(1938,1940)$ proposed an original "hydrological" flood routing method, which has become quite popular under the name of the Muskingum approach. The attribute "hydrological" to a flood routing model generally indicates that a finite river reach is taken into account by solving directly for the outflow discharges as a function of the inflow ones, while all the geomorphological characteristics

Correspondence to: E. Todini

(ezio.todini@unibo.it) and the hydraulic properties of the reach are lumped into a number of model parameters. For instance, other "hydrological" modelling approaches to flood routing are the Diffusion Analogy response function model (Hayami, 1951; Dooge, 1973; Todini and Bossi, 1986); the cascade of linear reservoirs (Nash, 1958) whose applicability to flood routing was demonstrated by Kalinin and Miljukov (1958) or the cascade of non-linear reservoirs developed as part of the TOPKAPI hydrological model (Liu and Todini, 2002; 2004).

In 1969, Cunge extended the Muskingum method to time variable parameters whose values could be determined as a function of a reference discharge, by recognizing that the original Muskingum approach could be viewed as a first order kinematic approximation of a diffusion wave model, but then converting it into a parabolic approach by proposing a particular estimation of its parameter values which would guarantee that the real diffusion would be equalled by the numerical diffusion.

The method has been widely and successfully used for discharge routing notwithstanding the fact that several authors pointed out that the approach displays a mass balance error that can reach values of 8 to 10\% (Tang et al. 1999; Tang and Samuels, 1999). Although many authors worked on the problem of the mass balance inconsistency (Ponce and Yevjevich, 1978; Koussis, 1983; Ponce and Chaganti, 1994; Tang et al., 1999; Tang and Samuels, 1999; Perumal et al., 2001), a conclusive and convincing reason was not demonstrated.

In addition to the lack of mass balance, an even more important inconsistency is generated by the variable parameter Muskingum, known as the Muskingum-Cunge (MC) approach, which apparently has never been reported in the literature; if one substitutes back into the Muskingum equations, the parameters derived using Cunge approach, two different and inconsistent values for the water volume stored in the channel, are obtained.

The above mentioned pitfalls of MC approach have provided the motivation for this paper and it was deemed

Published by Copernicus Publications on behalf of the European Geosciences Union. 
essential to revisit the Muskingum-Cunge model in order to find the causes and possibly to overcome the inconsistencies, since after 37 years from its development, the MC method has still a fundamental role in modern hydrology. First of all, the MC is widely used as the routing component of several distributed or semi-distributed hydrological models, in which case the preservation of the mass balance is an essential feature. Moreover, although several (more or less expensive) computer packages are available today that solve the full de Saint Venant equations (for instance SOBEK Stelling and Duinmeijer, 2003; Stelling and Verwey, 2005; MIKE11 - DHI Water \& Environment, 2000; HEC-RAS U.S. Army Corps of Engineers, 2005; and many others) the variable parameter $\mathrm{MC}$, is still widely used all throughout the world when the lack of knowledge of river cross sections does not justify the use of more complex routing models. Another attractive reason is that it can be easily programmed at practically no cost.

This paper describes the analysis that was carried out and the corrections that were found to be appropriate. The quality of the new results was then assessed by routing a test wave, specifically the asymmetrical wave proposed by Tang et al. (1999), through three channels with different cross sections (rectangular, triangular and trapezoidal), by varying the slope, the roughness, the space and time integration intervals. All the results obtained show that the new approach in all the cases fully complies with the requirements of preserving mass balance, and, at the same time, of satisfying the Muskingum equations.

Finally a comparison with MIKE11 (DHI Water \& Environment, 2000) shows that, when the parabolic approximation holds, the proposed algorithm is capable of closely approximating the full de Saint Venant equations results both in terms of discharge and water levels. This is obviously true provided that the original limitations of the kinematic wave model and of the Muskingum model, in all its variants, are taken into account: namely the approach can only be applied in river or channel reaches not affected by the downstream conditions and backwater effects.

\section{The derivation of the Muskingum variable parameter equations}

The derivation of the original Muskingum approach is based upon the following two equations (Eq. 1) written for a channel (or river) reach without lateral inflow.

$$
\left\{\begin{array}{l}
\frac{d S}{d t}=I-O \\
S=k \varepsilon I+k(1-\varepsilon) O
\end{array}\right.
$$

The first equation (Eq. 1a) represents the mass balance, globally applied to the reach between the upstream and the downstream sections, while the second one (Eq. 1b) expresses $S\left[L^{3}\right]$, the volume stored in the reach, as a simple linear combination of $I\left[L^{3} T^{-1}\right]$ the inflow discharge at the upstream section and $O\left[L^{3} T^{-1}\right]$ the outflow discharge at the downstream section. In Eq. (1), $k[T]$ and $\varepsilon$ [dimensionless] are the two model parameters to be determined from the observations. It will be noticed that the two Muskingum equations define the storage $S$ and its derivative $\frac{d S}{d t}$ as a function of the inflow $I$ and outflow $O$ discharges as well as of the two parameters $k$ and $\varepsilon$.

Note that although the original derivation assumes that the very basis of the Muskingum routing procedure is that the storage consists of both "prism" (level pool) storage and "wedge" storage that reflects the imbalance between inflow and outflow (e.g., Chow, 1964; Chow et al., 1988), the model can be more proficiently thought of as a two parameter "lumped" model at the river reach scale, the storage of which can be expressed at any point in time as in Eq. (1b).

In the classical derivation of the Muskingum model the second expression in Eq. (1b) is substituted into the first one to give:

$$
\frac{d[k \varepsilon I]}{d t}+\frac{d[k(1-\varepsilon) O]}{d t}=I-O
$$

and, by assuming that $k$ and $\varepsilon$ are constant in time one can write:

$k \varepsilon \frac{d I}{d t}+k(1-\varepsilon) \frac{d O}{d t}=I-O$

Equation (3) is then solved using a centred finite difference approach by expressing the various quantities as follows:

$$
\begin{aligned}
& I=\frac{I_{t+\Delta t}+I_{t}}{2} ; \quad O=\frac{O_{t+\Delta t}+O_{t}}{2} ; \frac{d I}{d t}=\frac{I_{t+\Delta t}-I_{t}}{\Delta t} ; \\
& \frac{d O}{d t}=\frac{O_{t+\Delta t}-O_{t}}{\Delta t}
\end{aligned}
$$

Substitution in Eq. (3) of the quantities defined in Eq. (4) yields:

$k \varepsilon \frac{I_{t+\Delta t}-I_{t}}{\Delta t}+k(1-\varepsilon) \frac{O_{t+\Delta t}-O_{t}}{\Delta t}$
$=\frac{I_{t+\Delta t}+I_{t}}{2}-\frac{O_{t+\Delta t}+O_{t}}{2}$

By multiplying both sides by $2 \Delta t$ the following expression can be found:

$$
\begin{aligned}
& 2 k \varepsilon\left(I_{t+\Delta t}-I_{t}\right)+2 k(1-\varepsilon)\left(O_{t+\Delta t}-O_{t}\right) \\
& =\Delta t\left(I_{t+\Delta t}+I_{t}\right)-\Delta t\left(O_{t+\Delta t}+O_{t}\right)
\end{aligned}
$$

which can be rewritten as:

$$
\begin{aligned}
& {[2 k(1-\varepsilon)+\Delta t] } O_{t+\Delta t}=[-2 k \varepsilon+\Delta t] I_{t+\Delta t} \\
&+[2 k \varepsilon+\Delta t] I_{t}+[2 k(1-\varepsilon)-\Delta t] O_{t}(7)
\end{aligned}
$$

to give:

$$
\begin{aligned}
O_{t+\Delta t}= & \frac{-2 k \varepsilon+\Delta t}{2 k(1-\varepsilon)+\Delta t} I_{t+\Delta t}+\frac{2 k \varepsilon+\Delta t}{2 k(1-\varepsilon)+\Delta t} I_{t} \\
& +\frac{2 k(1-\varepsilon)-\Delta t}{2 k(1-\varepsilon)+\Delta t} O_{t}
\end{aligned}
$$


Finally, Eq. (8) can be rewritten as:

$O_{t+\Delta t}=C_{1} I_{t+\Delta t}+C_{2} I_{t}+C_{3} O_{t}$

with the following substitutions:

$C_{1}=\frac{-2 k \varepsilon+\Delta t}{2 k(1-\varepsilon)+\Delta t} ; \quad C_{2}=\frac{2 k \varepsilon+\Delta t}{2 k(1-\varepsilon)+\Delta t} ;$

$C_{3}=\frac{2 k(1-\varepsilon)-\Delta t}{2 k(1-\varepsilon)+\Delta t}$

where $C_{1}, C_{2}$ and $C_{3}$ are three coefficients subject to the following property:

$C_{1}+C_{2}+C_{3}=1$

as can be easily verified.

Cunge (1969) extended the original Muskingum method to time variable parameters whose values could be determined as a function of a reference discharge. The clever idea of Cunge was to recognize that Eq. (9) of the original Muskingum approach was formally the same, and could be interpreted either as a kinematic wave model (a first order approximation of a diffusion wave model) or as a proper diffusive wave model, depending on the value of the adopted parameters. He also showed how Eq. (9) could be transformed into a proper diffusion wave model by introducing the appropriate diffusive effect through a particular estimation of the model parameter values. Cunge started from the following kinematic routing model

$\frac{\partial Q}{\partial t}+c \frac{\partial Q}{\partial x}=0$

where $Q\left[L^{3} T^{-1}\right]$ is the discharge, $x[L]$ the longitudinal coordinate, $t[T]$ the time coordinate, and $c\left[L T^{-1}\right]$ the celerity. He derived the following classical finite difference weighted approximation for the partial derivatives on a four points scheme:

$$
\begin{aligned}
& \frac{\partial Q}{\partial t} \approx \frac{\varepsilon\left(Q_{j}^{i+1}-Q_{j}^{i}\right)+(1-\varepsilon)\left(Q_{j+1}^{i+1}-Q_{j+1}^{i}\right)}{\Delta t} \\
& \frac{\partial Q}{\partial x} \approx \frac{\vartheta\left(Q_{j+1}^{i+1}-Q_{j}^{i+1}\right)+(1-\vartheta)\left(Q_{j+1}^{i}-Q_{j}^{i}\right)}{\Delta x}
\end{aligned}
$$

where $Q_{j+1}^{i+1}=Q((i+1) \Delta t,(j+1) \Delta x) ; Q_{j}^{i+1}$ $=Q((i+1) \Delta t, j \Delta x) ; \quad Q_{j+1}^{i}=Q(i \Delta t,(j+1) \Delta x)$;

$Q_{j}^{i}=Q(i \Delta t, j \Delta x), \varepsilon(0 \leq \varepsilon \leq 1)$ being the space weighting factor and $\vartheta(0 \leq \vartheta \leq 1)$ the time weighting factor.

This approximation leads to the following first order approximation of the kinematic wave equation (Eq. 12):

$$
\begin{aligned}
& \frac{\varepsilon\left(Q_{j}^{i+1}-Q_{j}^{i}\right)+(1-\varepsilon)\left(Q_{j+1}^{i+1}-Q_{j+1}^{i}\right)}{\Delta t} \\
& +c \frac{\vartheta\left(Q_{j+1}^{i+1}-Q_{j}^{i+1}\right)+(1-\vartheta)\left(Q_{j+1}^{i}-Q_{j}^{i}\right)}{\Delta x}=0
\end{aligned}
$$

which can be rewritten as

$$
\begin{aligned}
& \frac{\varepsilon\left(Q_{j}^{i+1}-Q_{j}^{i}\right)+(1-\varepsilon)\left(Q_{j+1}^{i+1}-Q_{j+1}^{i}\right)}{\Delta t} \\
& +\frac{c}{2} \frac{\left(Q_{j+1}^{i+1}-Q_{j}^{i+1}\right)+\left(Q_{j+1}^{i}-Q_{j}^{i}\right)}{\Delta x}=0
\end{aligned}
$$

by assuming a time centered scheme $\left(\vartheta=\frac{1}{2}\right)$.

Equation (16), after some algebraic manipulation can be transformed into

$Q_{j+1}^{i+1}=C_{1} Q_{j}^{i+1}+C_{2} Q_{j}^{i}+C_{3} Q_{j+1}^{i}$

where

$$
\begin{aligned}
C 1 & =\frac{-2 \Delta x \varepsilon+c \Delta t}{2 \Delta x(1-\varepsilon)+c \Delta t} ; \quad C 2=\frac{2 \Delta x \varepsilon+c \Delta t}{2 \Delta x(1-\varepsilon)+c \Delta t} ; \\
C 3 & =\frac{2 \Delta x(1-\varepsilon)-c \Delta t}{2 \Delta x(1-\varepsilon)+c \Delta t}
\end{aligned}
$$

Cunge also noted that substituting for $k=\frac{\Delta x}{c}$ and by taking $O_{t+\Delta t}=Q_{j+1}^{i+1} ; O_{t}=Q_{j+1}^{i} ; I_{t+\Delta t}=Q_{j}^{i+1} ; I_{t}=Q_{j}^{i}$, Eq. (17) becomes identical to Eq. (9). Nevertheless, one should be aware that these two equations have a totally different meaning. While Eq. (17) represents the solution of a partial differential equation, Eq. (9) is the solution of an ordinary differential equation after integration of the continuity of mass equation in space.

As a matter of fact, a formally similar equation, although with different parameter values, can also be obtained from the discretisation of any explicit parabolic or hyperbolic scheme. This is what gave to Cunge (1969) the idea for deriving his variable parameter formulation; by expanding the discharge $Q$ in Taylor series he showed that Eq. (17) represents a first order approximation, with second order residual equal zero, of the kinematic model given in Eq. (12), and, at the same time a linear approximation of the parabolic model of Eq. (19)

$$
\frac{\partial Q}{\partial t}+c \frac{\partial Q}{\partial x}-\frac{Q}{2 B S_{0}} \frac{\partial^{2} Q}{\partial x^{2}}=0
$$

with second order rounding error (also known as numerical diffusion), given by :

$R=\frac{c \Delta x}{2}(1-2 \varepsilon) \frac{\partial^{2} Q}{\partial x^{2}}+\cdots \cdots$

In Eq. (19), $B[L]$ is the surface width; $S_{0}$ [dimensionless] the bottom slope.

This result implies that Eq. (17) can also be interpreted as the solution of the parabolic model given in Eq. (19), provided that the following relation holds:

$\frac{c \Delta x}{2}(1-2 \varepsilon)=\frac{Q}{2 B S_{0}}$ 


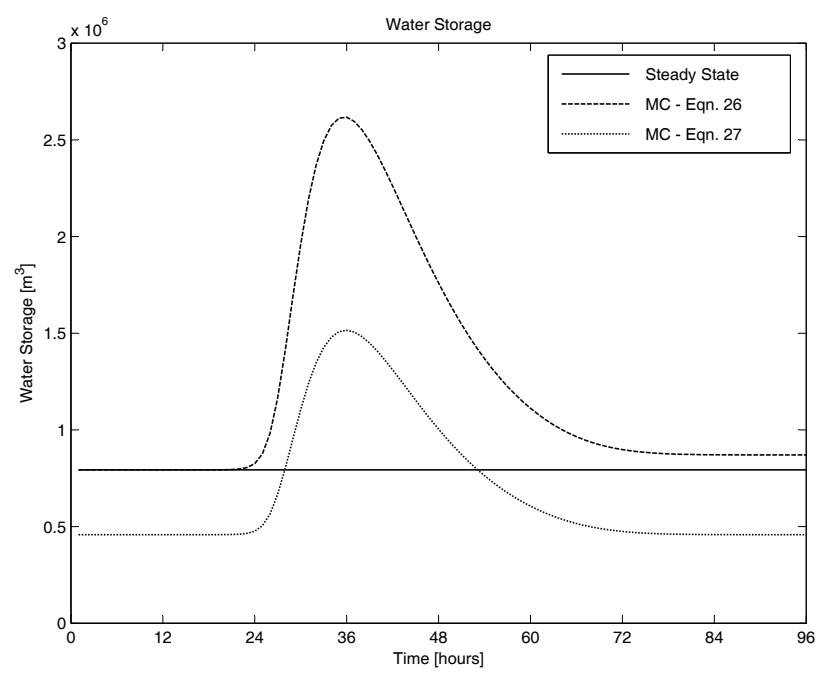

Fig. 1. Steady state volume (solid line) and storage volumes computed using Eq. (26) (dashed line) and Eq. (27) (dotted line).

Therefore, by imposing that the numerical diffusion equals the physical one (see also Szél and Gáspár, 2000; Wang et al., 2006), Cunge (1969) derived an expression for $\varepsilon$.

$\varepsilon=\frac{1}{2}\left(1-\frac{Q}{c \Delta x B S_{0}}\right)$

which was used, together with $k=\frac{\Delta x}{c}$ in Eq. (18), and updated at each time step, to give rise to the so called Variable Parameter Muskingum-Cunge approach. Successively, without changing the nature of the problem, Ponce and Yevjevich proposed (1978) the following expressions for $C_{1}, C_{2}, C_{3}$ :

$C_{1}=\frac{-1+C+D}{1+C+D} ; \quad C_{2}=\frac{1+C-D}{1+C+D} ; \quad C_{3}=\frac{1-C+D}{1+C+D}$

derived in terms of the dimensionless "Courant number" $(C)$; and "cell Reynolds number" $(D)$, which is the ratio of the physical and numerical diffusivities

$C=\frac{c \Delta t}{\Delta x} ; \quad D=\frac{Q}{B S_{0} c \Delta x}$

Several ways for estimating $Q$ and $c$ have been also proposed in the literature (Ponce and Chaganti, 1994; Tang et al., 1999; Wang et al., 2006) giving rise to a wide variety of three or four point schemes.

Parameters $C$ and $D$ are generally estimated, at each time interval, as a function of a reference discharge $Q$ relevant to each computation section in which a river reach will be divided. This poses certain limitations on the length $\Delta x$ of the computation section. $Q$, which will be evaluated at a central point, will be used to estimate the water stage and the other quantities of interest such as $B, c$ and finally $C$ and $D$. The larger $\Delta x$ is, the likelihood that the Muskingum hypothesis on the linear variation in space of the discharge will hold, decreases. Although, this property is also influenced by bed slope, friction and surface width, as a rule of thumb one should never exceed few kilometers (possibly one) to avoid errors which will be more evident in terms of water stage.

By comparing Eq. (10) and Eq. (23) one can finally derive the expressions for the two original Muskingum parameters:

$$
\left\{\begin{array}{l}
k=\frac{\Delta t}{C} \\
\varepsilon=\frac{1-D}{2}
\end{array}\right.
$$

The model with the two parameters estimated in every computation section of length $\Delta x$ and at each time step $\Delta t$ according to Eqs. (25) is known as the Muskingum-Cunge (MC) method and has been, and still is, widely used all over the world for routing discharges.

Unfortunately two inconsistencies have been detected in the practical use of MC. The first one, which relates to a loss of mass was identified by several authors and widely reported (see for instance Ponce and Yevjevich, 1978; Koussis, 1983; Ponce and Chaganti, 1994; Tang et al., 1999, Perumal et al., 2001) and recently interpreted as inversely proportional to the bed slope (Tang et al., 1999).

The second one, relates to the fact that if one discretises Eq. (1a), to estimate the storage in the reach, one obtains:

$S_{t+\Delta t}=S_{t}+\left(\frac{I_{t+\Delta t}+I_{t}}{2}-\frac{O_{t+\Delta t}+O_{t}}{2}\right) \Delta t$

The same storage can also be estimated by discretising Eq. (1b) and using the values for $k$ and $\varepsilon$ determined from Eqs. (25), which gives:

$S_{t+\Delta t}=k \varepsilon I_{t+\Delta t}+k(1-\varepsilon) O_{t+\Delta t}$

Astonishingly, no one seems to have checked back the effect of the Cunge variable parameter estimation on the two Muskingum basic equations. Paradoxically, not only do the two equations lead to different results, but neither of them is even consistent with the steady state conditions.

Without loss of generality, Fig. 1 shows the storage values, computed from Eqs. (26) and (27), for the base case with rectangular cross-section, which is described in the "Numerical experiment" section. From the figure, one can notice that (i) the stored volume computed using Eq. (26) does not return to the original steady state as a consequence of the above mentioned mass balance inconsistency (in practice the water is not lost, but rather stored in the channel reach) and (ii) Eq. (27) produces a storage which is always lower than it should be. In particular, the analysis of the steady state, namely when the inflow and outflow discharges are identical and Eq. (27) degenerates into $S_{t+\Delta t}=k I_{t+\Delta t}=k O_{t+\Delta t}$, reveals that this effect can only be attributed to a wrong value estimated for parameter $k$.

In this paper the reasons for the two inconsistencies will be analysed and explained starting from the above mentioned considerations, and a slightly modified algorithm, that does not change the nature and the simplicity of the variable parameter MC method, will be proposed. 


\section{Resolving the mass conservation inconsistency}

Several authors (Ponce and Yevjevich, 1978; Koussis, 1980; Ponce and Chaganti, 1994; Tang et al. 1999, Perumal et al., 2001) have reported that while the original constant parameter Muskingum perfectly preserves mass balance, the variable parameter Muskingum-Cunge suffers from a loss of mass which increases with the flatness of the bed slope, reaching values of the order of 8 to $10 \%$ at slopes of the order of $10^{-4}$ (Tang et al. 1999).

Most of the above mentioned authors have tried to find alternative numerical schemes to improve the conservation of mass (or continuity), but no real explanation was ever given for the causes of this loss of mass, since they did not realize that the actual reason was hidden in the original derivation of the Muskingum equation.

It is interesting to notice that the seed for the modification proposed in this paper can also be found in a comment by Cunge (2001). As can be seen in his comment, Cunge attributes the non-conservation mass to an inaccurate discretization by Tang et al. (1999), which, on the other hand is fully consistent with the Muskingum model formulation given by Eq. (3). Cunge does not seem to realize that the justification for the different discretization he proposes lies in a different derivation of the Muskingum model, which allows from the very beginning for the possibility of time variant parameters.

Not enough attention has been paid to the fact that the original derivation of the Muskingum approach "implies" time constant parameters with the consequence that Eq. (3) is only valid if $k$ and $\varepsilon$ are constant in time, which justifies the use of average values within a time interval as in Tang et al. (1999) and in most of the cited works. If one discretises Eq. (3), as was done to derive Eq. (5), it is quite evident that one is supposed to use constant $k$ and $\varepsilon$ in each time-step which creates the situation illustrated in Fig. 2. As can be seen in the figure, at the boundary between of two time steps (time step 1 between times $t-\Delta t$ and $t$ and time step 2 between times $t$ and $t+\Delta t$ ) the inflow and outflow discharges, $I_{t}$ and $O_{t}$ are the same in both time steps. However, this is not true for the volume stored in the reach, because of the following inequality:

$$
\begin{aligned}
S_{t}^{(2)} & =[k \varepsilon]_{2} I_{t}+[k(1-\varepsilon)]_{2} O_{t} \neq S_{t}^{(1)} \\
& =[k \varepsilon]_{1} I_{t}+[k(1-\varepsilon)]_{1} O_{t}
\end{aligned}
$$

since $[k \varepsilon]_{1}$ and $[k(1-\varepsilon)]_{1}$, the average parameter values in time step 1 are not constrained to be equal to $[k \varepsilon]_{2}$ and $[k(1-\varepsilon)]_{2}$, the average parameter values in time step 2 . This will result in a difference that will accumulate over time with the consequent mass conservation inconsistency.

On the contrary, if one assumes that $k$ and $\varepsilon$ may vary in time, Eq. (3) is no longer valid and one has to directly



Fig. 2. Storage values computed in two successive time steps. When using variable Muskingum-Cunge parameters, the storage value $S_{t}$ computed at time step $1\left(S_{t}^{(1)}\right)$ will differ from the one computed at time step $2\left(S_{t}^{(2)}\right)$, according to Eq. (28).

discretise Eq. (2), using the following definitions:

$$
\begin{aligned}
& I \simeq \frac{I_{t+\Delta t}+I_{t}}{2} ; \quad O \simeq \frac{O_{t+\Delta t}+O_{t}}{2} ; \frac{d[k \varepsilon I]}{d t} \\
& \simeq \frac{\Delta[k \varepsilon I]}{\Delta t}=\frac{[k \varepsilon]_{t+\Delta t} I_{t+\Delta t}-[k \varepsilon]_{t} I_{t}}{\Delta t} ; \frac{d[k(1-\varepsilon) O]}{d t} \\
& \simeq \frac{\Delta[k(1-\varepsilon) O]}{\Delta t}=\frac{[k(1-\varepsilon)]_{t+\Delta t} O_{t+\Delta t}-[k(1-\varepsilon)]_{t} O_{t}}{\Delta t}
\end{aligned}
$$

Note that the quantities $[k \varepsilon]$ and $[k(1-\varepsilon)]$ appearing in Eqs. (28) and (29) are put in square brackets to mark that in the sequel these, and not the original $k$ and $\varepsilon$, used in the steady-state Muskingum equations, will be considered as the actual time varying model parameters. Appendix A demonstrates the validity of the approximation implied in Eq. (29).

Substitution of the quantities defined in Eq. (29) into Eq. (2) yields:

$$
\begin{aligned}
& \frac{[k \varepsilon]_{t+\Delta t} I_{t+\Delta t}-[k \varepsilon]_{t} I_{t}}{\Delta t}+\frac{[k(1-\varepsilon)]_{t+\Delta t} O_{t+\Delta t}-[k(1-\varepsilon)]_{t} O_{t}}{\Delta t} \\
& =\frac{I_{t+\Delta t}+I_{t}}{2}-\frac{O_{t+\Delta t}+O_{t}}{2}
\end{aligned}
$$

as the valid time varying finite difference approximation for the variable parameter Muskingum approach.

As can be seen from Fig. 3, not only the inflow and outflow discharges are now equal at the boundary between two time steps, but also the volumes stored in the reach at that instant are the same when computed in either interval:

$S_{t}^{(2)}=[k \varepsilon]_{t} I_{t}+[k(1-\varepsilon)]_{t} O_{t}=S_{t}^{(1)}=[k \varepsilon]_{t} I_{t}+[k(1-\varepsilon)]_{t} O_{t}$

By multiplying both sides of Eq. (30) by $2 \Delta t$ the following expression is obtained:

$$
\begin{array}{r}
2[k \varepsilon]_{t+\Delta t} I_{t+\Delta t}-2[k \varepsilon]_{t} I_{t}+2[k(1-\varepsilon)]_{t+\Delta t} O_{t+\Delta t}-2[k(1-\varepsilon)]_{t} O_{t} \\
=\Delta t\left(I_{t+\Delta t}+I_{t}\right)-\Delta t\left(O_{t+\Delta t}+O_{t}\right)
\end{array}
$$




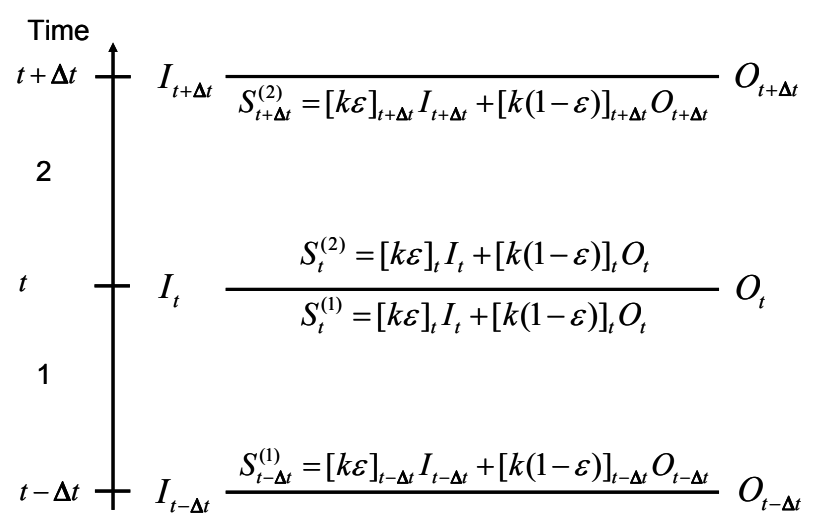

Fig. 3. Storage values computed in two successive time steps. When using variable Muskingum-Cunge parameters with the proposed correction, the storage value $S_{t}$ computed at time step $1\left(S_{t}^{(1)}\right)$ will equal the one computed at time step $2\left(S_{t}^{(2)}\right)$, according to Eq. (31).

which can be rewritten as:

$$
\begin{array}{r}
\left\{2[k(1-\varepsilon)]_{t+\Delta t}+\Delta t\right\} O_{t+\Delta t}=\left\{-2[k \varepsilon]_{t+\Delta t}+\Delta t\right\} I_{t+\Delta t} \\
+\left\{2[k \varepsilon]_{t}+\Delta t\right\} I_{t}+\left\{2[k(1-\varepsilon)]_{t}-\Delta t\right\} O_{t}
\end{array}
$$

to give:

$$
\begin{aligned}
& O_{t+\Delta t}=\frac{-2[k \varepsilon]_{t+\Delta t}+\Delta t}{2[k(1-\varepsilon)]_{t+\Delta t}+\Delta t} I_{t+\Delta t} \\
& +\frac{2[k \varepsilon]_{t}+\Delta t}{2[k(1-\varepsilon)]_{t+\Delta t}+\Delta t} I_{t}+\frac{2[k(1-\varepsilon)]_{t}-\Delta t}{2[k(1-\varepsilon)]_{t+\Delta t}+\Delta t} O_{t}
\end{aligned}
$$

Finally, Eq. (34) can be rewritten as:

$O_{t+\Delta t}=C_{1} I_{t+\Delta t}+C_{2} I_{t}+C_{3} O_{t}$

with the following substitutions:

$$
\begin{aligned}
C_{1} & =\frac{-2[k \varepsilon]_{t+\Delta t}+\Delta t}{2[k(1-\varepsilon)]_{t+\Delta t}+\Delta t} ; \quad C_{2}=\frac{2[k \varepsilon]_{t}+\Delta t}{2[k(1-\varepsilon)]_{t+\Delta t}+\Delta t} ; \\
C_{3} & =\frac{2[k(1-\varepsilon)]_{t}-\Delta t}{2[k(1-\varepsilon)]_{t+\Delta t}+\Delta t}
\end{aligned}
$$

where $C_{1}, C_{2}$ and $C_{3}$ are the three coefficients that still guarantee the property expressed by Eq. (11). The same parameters can also be obtained in terms of the Courant number and of the cell Reynolds number:

$$
\begin{aligned}
& C_{1}=\frac{-1+C_{t+\Delta t}+D_{t+\Delta t}}{1+C_{t+\Delta t}+D_{t+\Delta t}} ; \quad C_{2}=\frac{1+C_{t}-D_{t}}{1+C_{t+\Delta t}+D_{t+\Delta t}} \frac{C_{t+\Delta t}}{C_{t}} ; \\
& C_{3}=\frac{1-C_{t}+D_{t}}{1+C_{t+\Delta t}+D_{t+\Delta t}} \frac{C_{t+\Delta t}}{C_{t}}
\end{aligned}
$$

after substituting for:

$$
\left\{\begin{aligned}
{[k \varepsilon]_{t+\Delta t} } & =\frac{\left(1-D_{t+\Delta t}\right) \Delta t}{2 C_{t+\Delta t}} ;[k \varepsilon]_{t}=\frac{\left(1-D_{t}\right) \Delta t}{2 C_{t}} \\
{[k(1-\varepsilon)]_{t+\Delta t} } & =\frac{\left(1+D_{t+\Delta t}\right) \Delta t}{2 C_{t+\Delta t}} ;[k(1-\varepsilon)]_{t}=\frac{\left(1+D_{t}\right) \Delta t}{2 C_{t}}
\end{aligned}\right.
$$

This scheme is now mass conservative, but there is still an inconsistency between Eqs. (26) and (27).

To elaborate: Eq. (26) now leads to a storage $S_{t}$ that is consistent with the steady state, both at the beginning and at the end of a transient; however, Eq. (27) produces a result which is always different from the one produced by Eq. (26) and, in addition, is also not consistent with the expected steady state storage in the channel.

\section{Resolving the steady state inconsistency}

In order to resolve the steady state inconsistency, one needs to look in more detail into Eq. (27). If one substitutes for $[k \varepsilon]$ and $[k(1-\varepsilon)]$, given by Eqs. (25), into Eq. (27) written for a generic time $t$ (which is omitted for the sake of clarity), one obtains:

$S=\frac{\Delta t}{C} \frac{1-D}{2} I+\frac{\Delta t}{C} \frac{1+D}{2} O$

which can be re-arranged as:

$S=\frac{\Delta t}{C} \frac{O+I}{2}+\frac{\Delta t D}{C} \frac{O-I}{2}$

Clearly, $\frac{\Delta t}{C} \frac{O+I}{2}$, the first right hand side term in Eq. (40), represents the storage at steady state, since the second term vanishes due to the fact that the steady state is characterised by $I=O$. Consequently, $\frac{\Delta t D}{C} \frac{O-I}{2}$, the second right hand side term in Eq. (40), can be considered as the one governing the unsteady state dynamics.

In the case of steady flow, when $I=O=\frac{O+I}{2}=Q$, under the classical assumptions of the Muskingum model, together with the definition of discharge $Q=A v$, with $A$ the wetted area $\left[L^{2}\right]$, and $v$ the velocity $\left[L T^{-1}\right]$, the following result can be obtained for the storage:

$S=A \Delta x=\frac{Q}{v} \Delta x=k^{*} Q$

with $\Delta x$ the length of the computational interval $[L]$, and $k^{*}=\frac{\Delta x}{v}[T]$ the resulting steady state parameter, which can be interpreted as the time taken for a parcel of water to traverse the reach, as distinct from the kinematic celerity or wave speed.

It is not difficult to show that $k^{*} \neq k$. By substituting for $C$ given by Eq. (24) into Eq. (25a) one obtains the inequality:

$k=\frac{\Delta x}{c} \neq \frac{\Delta x}{v}=k^{*}$

This is not astonishing since the parabolic model derived by Cunge (1969), describes the movement, with celerity $c$, of the small perturbations by means of a partial differential equation, while the lumped Muskingum model (after integration in space of the continuity equation), is based upon an ordinary differential equation describing the mass movement, with velocity $v$, of the storage. 
Therefore, if one wants to be consistent with the steady state specialization of the Muskingum model, one needs to use $k^{*}$ instead of $k$. This can be easily done by defining a dimensionless correction coefficient $\beta=c / v$ and by dividing $C$ by $\beta, C^{*}=C / \beta=\frac{v \Delta t}{\Delta x}$ so that $k^{*}=\frac{\Delta t}{C^{*}}=\frac{\Delta x}{v}$.

This correction satisfies the steady state, but inevitably modifies the unsteady state dynamics, since the coefficient of the second right hand side term in Eq. (40) now becomes $\frac{\Delta t D}{C^{*}}$. It is therefore necessary to define $D^{*}=D / \beta$ so that:

$$
\frac{\Delta t D^{*}}{C^{*}}=\frac{\Delta t D}{C}
$$

By incorporating these results, Eq. (38) can finally be rewritten as:

$$
\left\{\begin{array}{c}
{[k \varepsilon]_{t+\Delta t}=\frac{\left(1-D_{t+\Delta t}^{*}\right) \Delta t}{2 C_{t+\Delta t}^{*} ;} \quad[k \varepsilon]_{t}=\frac{\left(1-D_{t}^{*}\right) \Delta t}{2 C_{t}^{*}}} \\
{[k(1-\varepsilon)]_{t+\Delta t}=\frac{\left(1+D_{t+\Delta t}^{*}\right) \Delta t}{2 C_{t+\Delta t}^{*}} ;[k(1-\varepsilon)]_{t}=\frac{\left(1+D_{t}^{*}\right) \Delta t}{2 C_{t}^{*}}}
\end{array}\right.
$$

These modifications do not alter the overall model dynamics, but allow Eq. (27) to satisfy the steady state condition. Figure 4 shows the results of the proposed modifications. The storage derived with Eq. (27) is now identical to the one produced by Eq. (26) and they both comply with the steady state condition.

As a final remark, please note that, the parameter $\varepsilon$ is allowed to take negative values that are legitimate in the variable parameter approaches such as the MC and the newly proposed one, without inducing neither numerical instability nor inaccuracy in the results, as demonstrated by Szél and Gáspár (2000).

\section{The new mass conservative and steady state consistent variable parameter Muskingum-Cunge method}

The formulation of the new algorithm, which will be referred in this paper as the variable parameter Muskingum-CungeTodini (MCT) method, is provided here for a generic cross section, which is assumed constant in space within a single reach.

A first guess estimate $\hat{O}_{t+\Delta t}$ for the outflow $O_{t+\Delta t}$ at time $t+\Delta t$ is initially computed as:

$\hat{O}_{t+\Delta t}=O_{t}+\left(I_{t+\Delta t}-I_{t}\right)$

Then the reference discharge is computed at times $t$ and $t+\Delta t$ as:

$Q_{t}=\frac{I_{t}+O_{t}}{2}$

$Q_{t+\Delta t}=\frac{I_{t+\Delta t}+\hat{O}_{t+\Delta t}}{2}$



Fig. 4. Steady state volume (thin solid line) and storage volumes computed either using Eq. (26) (dashed line) and Eq. (27) (dotted line) with $\beta=1$, or using both equations with $\beta=c / v$ (thick solid line).

where the reference water levels can be derived by means of a Newton-Raphson approach from the following implicit equations:

$y_{t}=y\left\{Q_{t}, n, S_{0}\right\}$

$y_{t+\Delta t}=y\left\{Q_{t+\Delta t}, n, S_{0}\right\}$

Details of the Newton-Raphson procedure can be found in Appendix B.

Using the reference discharge and water level it is then possible to estimate all the other quantities at times $t$ and $t+\Delta t$.

The celerity $c$ :

$c_{t}=c\left\{Q_{t}, y_{t}, n, S_{0}\right\}$

$c_{t+\Delta t}=c\left\{Q_{t+\Delta t}, y_{t+\Delta t}, n, S_{0}\right\}$

Note: the actual expressions for the celerity valid for triangular, rectangular and trapezoidal cross sections, are given in Appendix C.

The specialization of other necessary parameters follows. The correcting factor $\beta$ :

$\beta_{t}=\frac{c_{t} A_{t}}{Q_{t}}$

$\beta_{t+\Delta t}=\frac{c_{t+\Delta t} A_{t+\Delta t}}{Q_{t+\Delta t}}$ 
The corrected Courant number $C^{*}$ :

$C_{t}^{*}=\frac{c_{t}}{\beta_{t}} \frac{\Delta t}{\Delta x}$

$C_{t+\Delta t}^{*}=\frac{c_{t+\Delta t}}{\beta_{t+\Delta t}} \frac{\Delta t}{\Delta x}$

and the corrected cell Reynolds number $D^{*}$ :

$D_{t}^{*}=\frac{Q_{t}}{\beta_{t} B S_{0} c_{t} \Delta x}$

$D_{t+\Delta t}^{*}=\frac{Q_{t+\Delta t}}{\beta_{t+\Delta t} B S_{0} c_{t+\Delta t} \Delta x}$

Finally the MCT parameters are expressed as:

$C_{1}=\frac{-1+C_{t}^{*}+D_{t}^{*}}{1+C_{t+\Delta t}^{*}+D_{t+\Delta t}^{*}} ; C_{2}=\frac{1+C_{t}^{*}-D_{t}^{*}}{1+C_{t+\Delta t}^{*}+D_{t+\Delta t}^{*}} \frac{C_{t+\Delta t}^{*}}{C_{t}^{*}} ;$

$C_{3}=\frac{1-C_{t}^{*}+D_{t}^{*}}{1+C_{t+\Delta t}^{*}+D_{t+\Delta t}^{*}} \frac{C_{t+\Delta t}^{*}}{C_{t}^{*}}$

which yields the estimation of the flow at time $t+\Delta t$ through the standard formulation:

$\hat{O}_{t+\Delta t}=C_{1} I_{t+\Delta t}+C_{2} I_{t}+C_{3} O_{t}$

Note that while it is advisable to repeat twice the computations of Eqs. (46b), (47b), (48b), (49b), (50b), (51b), (52) and (53), in order to eliminate the influence of the first guess $\hat{O}_{t+\Delta t}$ given by Eq. (45), it is only necessary to compute Eqs. (46a), (47a), (48a), (49a), (50a), (51a) once at time $t=0$, since for $t>0$ one can use the value estimated at the previous time step .

Once $\hat{O}_{t+\Delta t}$ is known, one can estimate the storage at time $t+\Delta t$ as

$S_{t+\Delta t}=\frac{\left(1-D_{t+\Delta t}^{*}\right) \Delta t}{2 C_{t+\Delta t}^{*}} I_{t+\Delta t}+\frac{\left(1+D_{t+\Delta t}^{*}\right) \Delta t}{2 C_{t+\Delta t}^{*}} O_{t+\Delta t}$

by substituting for $[k \varepsilon]$ and $[k(1-\varepsilon)]$ given by Eqs. (44) into Eq. (27) and by setting $O_{t+\Delta t}=\hat{O}_{t+\Delta t}$.

Eventually, the water stage can be estimated, by taking into account that the Muskingum model is a lumped model in space, which means that the water level will represent the "average" water level in the reach. This differs from the estimation of the water stage proposed by Ponce and Lugo (2001) since they incorporate the estimation of the water stage in the four points scheme used to solve the kinematic/parabolic interpretation of the Muskingum equation, which is not a lumped model.

Therefore, taking into account the lumped nature of the MCT equation, one can estimate the average wetted area in the river reach:

$\bar{A}_{t+\Delta t}=\frac{S_{t+\Delta t}}{\Delta x}$ from which, knowing the shape of the cross section, the water stage can be evaluated:

$y_{t+\Delta t}=y\left\{\bar{A}_{t+\Delta t}\right\}$

Equation (56) represents the average water stage in the reach and, on the basis of the Muskingum wedge assumption can be interpreted as the water stage more or less in the centre of the reach. This should not be considered as a problem, given that most of the classical models (see for instance MIKE11 DHI Water \& Environment, 2000) in order to produce mass conservative schemes (Patankar, 1980), correctly discretise the full de Saint Venant equations using alternated grid points where the water stage (potential energy) and flow (kinetic energy) are alternatively computed along the river.

\section{The role of the "pressure term"}

Cappelaere (1997), discussed the advantages of an accurate diffusive wave routing procedure and the possibility of introducing a "pressure correcting term" to improve its accuracy. He also acknowledged the fact that variable parameter Advection Diffusion Equation (ADE) models (Price, 1973; Bocquillon and Moussa, 1988) do not guarantee mass conservation. He concludes by stating that the introduction of the pressure term "increasing model compliance with the fundamental de Saint Venant equations guarantees that the basic principles of momentum and mass conservation are better satisfied....".

In reality, because the proposed MCT is mass conservative, the introduction of the pressure term correction has no effect on mass conservation. Nonetheless, the introduction of the pressure correction term, on the basis that the parabolic approximation uses the water surface slope instead of the bottom slope to approximate the head slope, certainly improves the dynamical behaviour of the algorithm. This will be shown in the sequel through a numerical example.

\section{Numerical example}

In this study, in addition to the basic channels adopted in the Flood Studies Report (FSR) (NERC 1975), namely a rectangular channel (with a width $B=50 \mathrm{~m}$, a Manning's coefficient $n=0.035$, and a total channel length $L=100 \mathrm{~km}$, but with different bed slopes $S_{0}$ ranging from $10^{-3}$ to $10^{-4}$ ), a triangular and a trapezoidal channel were also analysed. Both the triangular and the trapezoidal channels are supposed to be contained by dykes with a slope ratio (elevation/width) $\tan (\alpha)=1 / 5$ while the trapezoidal channels have a bottom width $B_{0}=15 \mathrm{~m}$ (Fig. 5).

A synthetic inflow hydrograph (NERC 1975) was defined as

$Q(t)=Q_{\text {base }}+\left(Q_{\text {peak }}-Q_{\text {base }}\right)\left[\frac{t}{T_{p}} \exp \left(1-\frac{t}{T_{p}}\right)\right]^{\beta}$ 
Table 1. Variation of parameters and integration steps around the base case (in bold).

\begin{tabular}{crrrrr}
\hline $\mathrm{S}_{O}$ & 0.002 & 0.001 & 0.0005 & $\mathbf{0 . 0 0 0 2 5}$ & 0.0001 \\
$\mathrm{n}$ & 0.01 & 0.02 & $\mathbf{0 . 0 3 5}$ & 0.04 & 0.06 \\
$\Delta \mathrm{x}$ & 1000 & $\mathbf{2 0 0 0}$ & 4000 & 6000 & 8000 \\
$\Delta \mathrm{t}$ & 900 & $\mathbf{1 8 0 0}$ & 3600 & 5400 & 7200 \\
\hline
\end{tabular}

where $\beta=16 ; Q_{\text {peak }}=900 \mathrm{~m}^{3} \mathrm{~s}^{-1} ; Q_{\text {base }}=100 \mathrm{~m}^{3} \mathrm{~s}^{-1}$; and $T_{p}=24 \mathrm{~h}$.

For each cross section (rectangular, triangular and trapezoidal) a reference run was defined with the following parameters:

$S_{0}=0.00025$

$n=0.035 \mathrm{~m}^{-1 / 3} \mathrm{~s}$

$\Delta x=2000 \mathrm{~m}$

$\Delta t=1800 \mathrm{~s}$

In addition, each parameter was perturbed, as in Table 1, in order to analyse its effect on the preservation of the volume, the peak flow and relevant time of occurrence, the peak level and relevant time of occurrence.

The results of the experiment are given in Table 2, when the MCT is used without Cappelaere (1997) proposed correction and in Table 3 when the correction is applied.

The tables are divided into three columns representing the different cross sections used and in four rows relevant to the variation of bottom slope $\left(S_{0}\right)$, friction $(n)$, space integration interval $(\Delta x)$ and time integration interval $(\Delta t)$.

As one can see from Table 2, as opposed to the incomplete effectiveness of empirical corrections, such as the one proposed by Tang et al. (1999), when using the MCT approach the volume error remains equal to zero in all the examined cases independently from the variation of bottom slope, friction, space and time integration intervals and Cappelaere correction. Moreover, Table 3 shows that this is also true when this correction is applied.

In particular, Tables 2 and 3 one should note that the effect induced by the variation of the bed slope and the friction coefficient is always consistent with that expected. More interesting is the fact that relatively small effects on the peak flow and its time of occurrence, as well as on the peak level and the time of its occurrence, are produced by the variation of the integration time and space steps.

Nonetheless, one should realize that in the numerical example, the bottom slope, the shape of the channel, the friction, etc. are constant, which is not the case in real rivers, where the bottom slope and the cross section shape and all the other characteristics change continuously. Given the wide number of different cases, there is no unique rule, but in real world application one must divide a river reach into a number

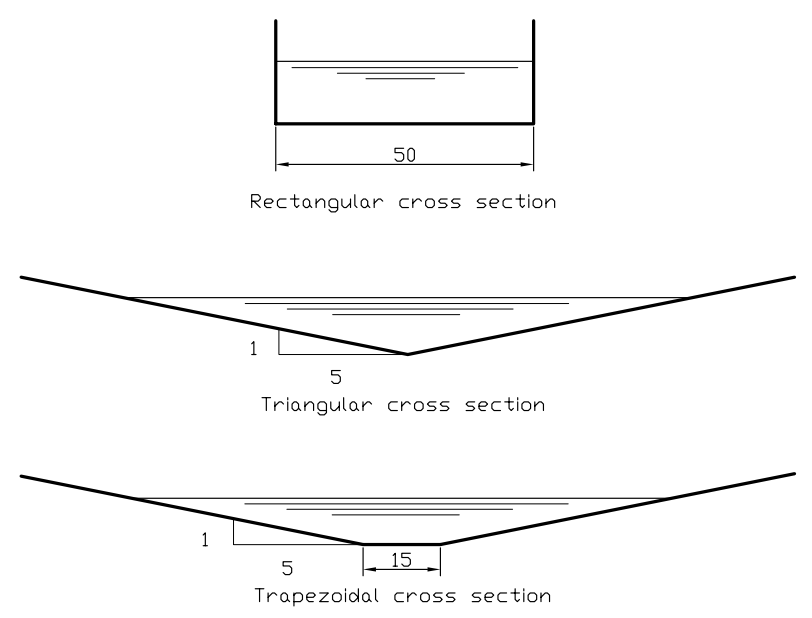

Fig. 5. The three cross sections shapes (rectangular, triangular and trapezoidal) and the relevant dimensions used in the numerical experiment.

of computation sections of limited length, for which the hypothesis of constant bed slope, shape and friction, as well as linear variation of the discharge, required by the Muskingum approach, is a consistent approximation. On the same lines, the integration time interval must be sufficiently small to allow the user to correctly represent the peak flow and stage in terms of magnitude (they obviously become smoothed if the time-step is too long) and time of occurrence.

Figures 6 and 7, which were derived using the reference run parameters, show the behaviour of the original variable parameter Muskingum-Cunge (MC) approach when compared to the MCT and the MCT with the Cappelaere correction $(\mathrm{MCT}+\mathrm{C})$, for the base case applied to the rectangular channel. It is easy to note from Figure 6 that the MC peak discharge is anticipated and much higher than the ones produced by the MCT and the MCT+C. Moreover Fig. 7 shows how the MC water level, as opposed to the ones produced by MCT and MCT $+\mathrm{C}$, does not return to the steady state at the end of the transient.

Finally to understand the hydraulic improvement obtained by the MCT and the MCT+C, their results were compared to the ones produced using a full de Saint Venant approach (MIKE11 - DHI Water \& Environment, 2000).

Figures 8 and 9 show the results in terms of discharge and water levels for the rectangular cross section; Figs. 10 and 11 show the results for the triangular cross section; and Figs. 12 and 13 show the results for the trapezoidal cross section. In the case of the rectangular section the results of the MCT+C perfectly match the results of MIKE11, while in the case of the triangular and the trapezoidal cross sections, the results, although not perfectly matching the ones produced by MIKE11, are very good approximations.

The rather small differences appearing in these two cases may depend (1) on the difference in the representation of the 
Table 2. Variation of MCT results without Cappalaere (1997) proposed correction. Base case in bold.

\begin{tabular}{|c|c|c|c|c|c|c|c|c|c|c|c|c|c|c|c|}
\hline \multirow[b]{2}{*}{$\mathrm{S}_{o}$} & \multicolumn{5}{|c|}{ Rectangular Cross Section } & \multicolumn{5}{|c|}{ Triangular Cross Section } & \multicolumn{5}{|c|}{ Trapezoidal Cross Section } \\
\hline & {$\left[\mathrm{m}^{3} \mathrm{~s}_{\max }^{-1}\right]$} & $\begin{array}{r}\mathrm{i} \Delta \mathrm{t} \\
\left(\mathrm{Q}_{\max }\right)\end{array}$ & $\begin{array}{r}\mathrm{H}_{\max } \\
{[\mathrm{m}]}\end{array}$ & $\begin{array}{c}\mathrm{i} \Delta \mathrm{t} \\
\left(\mathrm{H}_{\max }\right)\end{array}$ & $\begin{array}{r}\text { Vol. err } \\
\%\end{array}$ & $\begin{array}{r}\mathrm{Q}_{\max } \\
{\left[\mathrm{m}^{3} \mathrm{~s}^{-1}\right]}\end{array}$ & $\begin{array}{r}\mathrm{i} \Delta \mathrm{t} \\
\left(\mathrm{Q}_{\max }\right)\end{array}$ & $\begin{array}{r}\mathrm{H}_{\max } \\
{[\mathrm{m}]}\end{array}$ & $\begin{array}{c}\mathrm{i} \Delta \mathrm{t} \\
\left(\mathrm{H}_{\max }\right)\end{array}$ & $\begin{array}{r}\text { Vol. err } \\
\%\end{array}$ & $\begin{array}{r}\mathrm{Q}_{\max } \\
{\left[\mathrm{m}^{3} \mathrm{~s}^{-1}\right]}\end{array}$ & $\begin{array}{r}\mathrm{i} \Delta \mathrm{t} \\
\left(\mathrm{Q}_{\max }\right)\end{array}$ & $\begin{array}{r}\mathrm{H}_{\max } \\
{[\mathrm{m}]}\end{array}$ & $\begin{array}{r}\mathrm{i} \Delta \mathrm{t} \\
\left(\mathrm{H}_{\max }\right) \%\end{array}$ & Vol. err \\
\hline 0.002 & 894.68 & 61 & 5.26 & 61 & 0.00 & 892.80 & 64 & 7.62 & 64 & 0.00 & 892.95 & 64 & 6.29 & 64 & 0.00 \\
\hline 0.001 & 879.10 & 64 & 6.51 & 64 & 0.00 & 873.11 & 68 & 8.60 & 68 & 0.00 & 873.65 & 68 & 7.26 & 68 & 0.00 \\
\hline 0.0005 & 819.78 & 68 & 7.81 & 69 & 0.00 & 802.64 & 74 & 9.49 & 75 & 0.00 & 804.27 & 74 & 8.14 & 75 & 0.00 \\
\hline 0.00025 & 669.53 & 75 & 8.54 & 77 & 0.00 & 641.17 & 83 & 9.91 & 86 & 0.00 & 643.74 & 83 & 8.56 & 86 & 0.00 \\
\hline 0.0001 & 423.11 & 77 & 8.32 & 89 & 0.00 & 391.80 & 93 & 9.70 & 103 & 0.00 & 393.72 & 93 & 8.36 & 103 & 0.00 \\
\hline $\begin{array}{l}\mathrm{n} \\
{\left[\mathrm{m}^{-3} \mathrm{~s}\right]}\end{array}$ & $\begin{array}{r}\mathrm{Q}_{\max } \\
{\left[\mathrm{m}^{3} \mathrm{~s}^{-1}\right]}\end{array}$ & $\begin{array}{r}\mathrm{i} \Delta \mathrm{t} \\
\left(\mathrm{Q}_{\max }\right)\end{array}$ & $\begin{array}{r}\mathrm{H}_{\max } \\
{[\mathrm{m}]}\end{array}$ & $\begin{array}{c}\mathrm{i} \Delta \mathrm{t} \\
\left(\mathrm{H}_{\max }\right)\end{array}$ & $\begin{array}{r}\text { Vol. err } \\
\%\end{array}$ & $\begin{array}{r}\mathrm{Q}_{\max } \\
{\left[\mathrm{m}^{3} \mathrm{~s}^{-1}\right]}\end{array}$ & $\begin{array}{r}\mathrm{i} \Delta \mathrm{t} \\
\left(\mathrm{Q}_{\max }\right)\end{array}$ & $\begin{array}{r}\mathrm{H}_{\max } \\
{[\mathrm{m}]}\end{array}$ & $\begin{array}{c}\mathrm{i} \Delta \mathrm{t} \\
\left(\mathrm{H}_{\max }\right)\end{array}$ & $\begin{array}{r}\text { Vol. err } \\
\%\end{array}$ & $\begin{array}{r}\mathrm{Q}_{\max } \\
{\left[\mathrm{m}^{3} \mathrm{~s}^{-1}\right]}\end{array}$ & $\begin{array}{r}\mathrm{i} \Delta \mathrm{t} \\
\left(\mathrm{Q}_{\max }\right)\end{array}$ & $\begin{array}{r}\mathrm{H}_{\max } \\
{[\mathrm{m}]}\end{array}$ & $\begin{array}{c}\mathrm{i} \Delta \mathrm{t} \\
\left(\mathrm{H}_{\max }\right)\end{array}$ & $\begin{array}{r}\text { Vol. err } \\
\%\end{array}$ \\
\hline 0.01 & 873.19 & 59 & 4.52 & 60 & 0.00 & 862.15 & 62 & 6.94 & 62 & 0.00 & 863.26 & 62 & 5.63 & 62 & 0.00 \\
\hline 0.02 & 801.63 & 66 & 6.67 & 67 & 0.00 & 776.52 & 71 & 8.65 & 72 & 0.00 & 778.72 & 71 & 7.31 & 72 & 0.00 \\
\hline 0.035 & 669.53 & 75 & 8.54 & 77 & 0.00 & 641.17 & 83 & 9.91 & 86 & 0.00 & 643.74 & 83 & 8.56 & 86 & 0.00 \\
\hline 0.04 & 630.09 & 77 & 8.96 & 80 & 0.00 & 603.12 & 87 & 10.18 & 90 & 0.00 & 605.61 & 87 & 8.83 & 90 & 0.00 \\
\hline 0.06 & 505.99 & 87 & 10.12 & 92 & 0.00 & 486.19 & 102 & 10.92 & 106 & 0.00 & 488.26 & 102 & 9.56 & 106 & 0.00 \\
\hline $\begin{array}{l}\Delta \mathrm{x} \\
{[\mathrm{m}]}\end{array}$ & $\begin{array}{r}\mathrm{Q}_{\max } \\
{\left[\mathrm{m}^{3} \mathrm{~s}^{-1}\right]}\end{array}$ & $\begin{array}{r}\mathrm{i} \Delta \mathrm{t} \\
\left(\mathrm{Q}_{\max }\right)\end{array}$ & $\begin{array}{r}\mathrm{H}_{\max } \\
{[\mathrm{m}]}\end{array}$ & $\begin{array}{r}\mathrm{i} \Delta \mathrm{t} \\
\left(\mathrm{H}_{\max }\right)\end{array}$ & $\begin{array}{r}\text { Vol. err } \\
\%\end{array}$ & $\begin{array}{r}\mathrm{Qmax}_{\max } \\
{\left[\mathrm{m}^{3} \mathrm{~s}^{-1}\right]}\end{array}$ & $\begin{array}{r}\mathrm{i} \Delta \mathrm{t} \\
\left(\mathrm{Q}_{\max }\right)\end{array}$ & $\begin{array}{r}\mathrm{H}_{\max } \mathrm{r} \\
{[\mathrm{m}]}\end{array}$ & $\begin{array}{r}\mathrm{i} \Delta \mathrm{t} \\
\left(\mathrm{H}_{\max }\right)\end{array}$ & $\begin{array}{r}\text { Vol. err } \\
\%\end{array}$ & $\begin{array}{r}\mathrm{Qmax}_{\max } \\
{\left[\mathrm{m}^{3} \mathrm{~s}^{-1}\right]}\end{array}$ & $\begin{array}{r}\mathrm{i} \Delta \mathrm{t} \\
\left(\mathrm{Q}_{\max }\right)\end{array}$ & $\begin{array}{r}\mathrm{H}_{\max } \\
{[\mathrm{m}]}\end{array}$ & $\begin{array}{r}\mathrm{i} \Delta \mathrm{t} \\
\left(\mathrm{H}_{\max }\right)\end{array}$ & $\begin{array}{r}\text { Vol. err } \\
\%\end{array}$ \\
\hline 1000 & 669.51 & 75 & 8.54 & 77 & 0.00 & 641.12 & 83 & 9.91 & 86 & 0.00 & 643.69 & 83 & 8.56 & 86 & 0.00 \\
\hline 2000 & 669.53 & 75 & 8.54 & 77 & 0.00 & 641.17 & 83 & 9.91 & 86 & 0.00 & 643.74 & 83 & 8.56 & 86 & 0.00 \\
\hline 4000 & 669.62 & 75 & 8.56 & 77 & 0.00 & 641.38 & 83 & 9.92 & 85 & 0.00 & 643.94 & 83 & 8.57 & 85 & 0.00 \\
\hline 6000 & 675.69 & 74 & 8.62 & 76 & 0.00 & 648.35 & 82 & 9.97 & 83 & 0.00 & 650.83 & 82 & 8.61 & 83 & 0.00 \\
\hline 8000 & 675.92 & 73 & 8.63 & 75 & 0.00 & 648.75 & 82 & 9.98 & 83 & 0.00 & 651.22 & 82 & 8.62 & 83 & 0.00 \\
\hline $\begin{array}{l}\Delta \mathrm{t} \\
{[\mathrm{s}]}\end{array}$ & $\begin{array}{r}\mathrm{Q}_{\max } \\
{\left[\mathrm{m}^{3} \mathrm{~s}^{-1}\right]}\end{array}$ & $\begin{array}{r}\mathrm{i} \Delta \mathrm{t} \\
\left(\mathrm{Q}_{\max }\right)\end{array}$ & $\begin{array}{r}\mathrm{H}_{\max } \\
{[\mathrm{m}]}\end{array}$ & $\begin{array}{c}\mathrm{i} \Delta \mathrm{t} \\
\left(\mathrm{H}_{\max }\right)\end{array}$ & $\begin{array}{r}\text { Vol. err } \\
\%\end{array}$ & $\begin{array}{r}\mathrm{Q}_{\max } \\
{\left[\mathrm{m}^{3} \mathrm{~s}^{-1}\right]}\end{array}$ & $\begin{array}{r}\mathrm{i} \Delta \mathrm{t} \\
\left(\mathrm{Q}_{\max }\right)\end{array}$ & $\begin{array}{r}\mathrm{H}_{\max } \mathrm{r} \\
{[\mathrm{m}]}\end{array}$ & $\begin{array}{r}\mathrm{i} \Delta \mathrm{t} \\
\left(\mathrm{H}_{\max }\right)\end{array}$ & $\begin{array}{r}\text { Vol. err } \\
\%\end{array}$ & $\begin{array}{r}\mathrm{Q}_{\max } \\
{\left[\mathrm{m}^{3} \mathrm{~s}^{-1}\right]}\end{array}$ & $\begin{array}{r}\mathrm{i} \Delta \mathrm{t} \\
\left(\mathrm{Q}_{\max }\right)\end{array}$ & $\begin{array}{r}\mathrm{H}_{\max } \\
{[\mathrm{m}]}\end{array}$ & $\begin{array}{r}\mathrm{i} \Delta \mathrm{t} \\
\left(\mathrm{H}_{\max }\right)\end{array}$ & $\begin{array}{r}\text { Vol. err } \\
\%\end{array}$ \\
\hline 900 & 669.65 & 149 & 8.54 & 155 & 0.00 & 641.36 & 167 & 9.91 & 171 & 0.00 & 643.89 & 167 & 8.56 & 171 & 0.00 \\
\hline 1800 & 669.53 & 75 & 8.54 & 77 & 0.00 & 641.17 & 83 & 9.91 & 86 & 0.00 & 643.74 & 83 & 8.56 & 86 & 0.00 \\
\hline 3600 & 669.15 & 37 & 8.54 & 39 & 0.00 & 641.16 & 42 & 9.91 & 43 & 0.00 & 643.68 & 42 & 8.56 & 43 & 0.00 \\
\hline 5400 & 669.55 & 25 & 8.54 & 26 & 0.00 & 641.25 & 28 & 9.91 & 29 & 0.00 & 643.79 & 28 & 8.56 & 29 & 0.00 \\
\hline 7200 & 668.43 & 19 & 8.52 & 19 & 0.00 & 641.28 & 21 & 9.90 & 22 & 0.00 & 643.86 & 21 & 8.54 & 22 & 0.00 \\
\hline
\end{tabular}



Fig. 6. Comparison of the discharge results obtained using the variable parameter Muskingum-Cunge (dashed line), the new scheme (dotted line) and the new scheme with the Cappelaere (1997) correction (solid line).

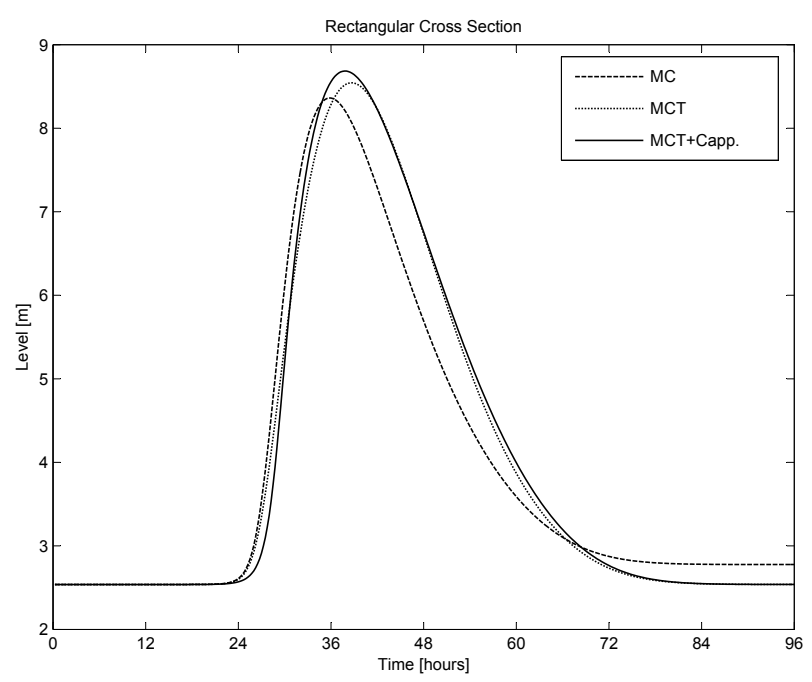

Fig. 7. Comparison of the water stage results obtained using the variable parameter Muskingum-Cunge (dashed line), the new scheme (dotted line) and the new scheme with the Cappelaere (1997) correction (solid line). Note that the Muskingum-Cunge does not return to the steady state. 
Table 3. Variation of MCT results with Cappalaere (1997) proposed correction. Base case in bold.

\begin{tabular}{|c|c|c|c|c|c|c|c|c|c|c|c|c|c|c|c|}
\hline \multirow[b]{2}{*}{$\mathrm{S}_{o}$} & \multicolumn{5}{|c|}{ Rectangular Cross Section } & \multicolumn{5}{|c|}{ Triangular Cross Section } & \multicolumn{5}{|c|}{ Trapezoidal Cross Section } \\
\hline & $\begin{array}{r}\mathrm{Q}_{\max } \\
{\left[\mathrm{m}^{3} \mathrm{~s}^{-1}\right]}\end{array}$ & $\begin{array}{r}\mathrm{i} \Delta \mathrm{t} \\
\left(\mathrm{Q}_{\max }\right)\end{array}$ & $\begin{array}{r}\mathrm{H}_{\max } \\
{[\mathrm{m}]}\end{array}$ & $\begin{array}{c}\mathrm{i} \Delta \mathrm{t} \\
\left(\mathrm{H}_{\max }\right)\end{array}$ & $\begin{array}{r}\text { Vol. err } \\
\%\end{array}$ & $\begin{array}{r}\mathrm{Q}_{\max } \\
{\left[\mathrm{m}^{3} \mathrm{~s}^{-1}\right]}\end{array}$ & $\begin{array}{r}\mathrm{i} \Delta \mathrm{t} \\
\left(\mathrm{Q}_{\max }\right)\end{array}$ & $\begin{array}{r}\mathrm{H}_{\max } \\
{[\mathrm{m}]}\end{array}$ & $\begin{array}{r}\mathrm{i} \Delta \mathrm{t} \\
\left(\mathrm{H}_{\max }\right)\end{array}$ & $\begin{array}{r}\text { Vol. err } \\
\%\end{array}$ & $\begin{array}{r}\mathrm{Q}_{\max } \\
{\left[\mathrm{m}^{3} \mathrm{~s}^{-1}\right]}\end{array}$ & $\begin{array}{r}\mathrm{i} \Delta \mathrm{t} \\
\left(\mathrm{Q}_{\max }\right)\end{array}$ & $\begin{array}{r}\mathrm{H}_{\max } \\
{[\mathrm{m}]}\end{array}$ & $\begin{array}{r}\mathrm{i} \Delta \mathrm{t} \\
\left(\mathrm{H}_{\max }\right) \%\end{array}$ & Vol. err \\
\hline 0.002 & 894.68 & 61 & 5.26 & 61 & 0.00 & 892.80 & 64 & 7.62 & 64 & 0.00 & 892.96 & 64 & 6.29 & 64 & 0.00 \\
\hline 0.001 & 879.20 & 64 & 6.51 & 64 & 0.00 & 873.31 & 68 & 8.60 & 68 & 0.00 & 873.84 & 68 & 7.26 & 68 & 0.00 \\
\hline 0.0005 & 823.13 & 68 & 7.83 & 69 & 0.00 & 806.79 & 74 & 9.51 & 78 & 0.00 & 808.19 & 74 & 8.15 & 75 & 0.00 \\
\hline 0.00025 & 687.00 & 73 & 8.69 & 76 & 0.00 & 655.86 & 82 & 10.00 & 84 & 0.00 & 658.18 & 82 & 8.64 & 84 & 0.00 \\
\hline 0.0001 & 450.41 & 76 & 8.64 & 86 & 0.00 & 400.71 & 91 & 9.78 & 100 & 0.00 & 402.78 & 92 & 8.44 & 100 & 0.00 \\
\hline $\begin{array}{l}\mathrm{n} \\
{\left[\mathrm{m}^{-3} \mathrm{~s}\right]}\end{array}$ & $\begin{array}{r}\mathrm{Q}_{\max } \\
{\left[\mathrm{m}^{3} \mathrm{~s}^{-1}\right]}\end{array}$ & $\begin{array}{r}\mathrm{i} \Delta \mathrm{t} \\
\left(\mathrm{Q}_{\max }\right)\end{array}$ & $\begin{array}{r}\mathrm{H}_{\max } \\
{[\mathrm{m}]}\end{array}$ & $\begin{array}{c}\mathrm{i} \Delta \mathrm{t} \\
\left(\mathrm{H}_{\max }\right)\end{array}$ & $\begin{array}{r}\text { Vol. err } \\
\%\end{array}$ & $\begin{array}{r}\mathrm{Q}_{\max } \\
{\left[\mathrm{m}^{3} \mathrm{~s}^{-1}\right]}\end{array}$ & $\begin{array}{r}\mathrm{i} \Delta \mathrm{t} \\
\left(\mathrm{Q}_{\max }\right)\end{array}$ & $\begin{array}{r}\mathrm{H}_{\max } \\
{[\mathrm{m}]}\end{array}$ & $\begin{array}{r}\mathrm{i} \Delta \mathrm{t} \\
\left(\mathrm{H}_{\max }\right)\end{array}$ & $\begin{array}{r}\text { Vol. err } \\
\%\end{array}$ & $\begin{array}{r}\mathrm{Q}_{\max } \\
{\left[\mathrm{m}^{3} \mathrm{~s}^{-1}\right]}\end{array}$ & $\begin{array}{r}\mathrm{i} \Delta \mathrm{t} \\
\left(\mathrm{Q}_{\max }\right)\end{array}$ & $\begin{array}{r}\mathrm{H}_{\max } \\
{[\mathrm{m}]}\end{array}$ & $\begin{array}{c}\mathrm{i} \Delta \mathrm{t} \\
\left(\mathrm{H}_{\max }\right)\end{array}$ & $\begin{array}{r}\text { Vol. err } \\
\%\end{array}$ \\
\hline 0.01 & 873.81 & 59 & 4.52 & 60 & 0.00 & 862.99 & 62 & 6.94 & 62 & 0.00 & 864.03 & 62 & 5.64 & 62 & 0.00 \\
\hline 0.02 & 807.27 & 65 & 6.71 & 67 & 0.00 & 783.17 & 70 & 8.68 & 72 & 0.00 & 785.09 & 70 & 7.34 & 72 & 0.00 \\
\hline 0.035 & 687.00 & 73 & 8.69 & 76 & 0.00 & 655.86 & 82 & 10.00 & 84 & 0.00 & 658.18 & 82 & 8.64 & 84 & 0.00 \\
\hline 0.04 & 649.05 & 75 & 9.14 & 78 & 0.00 & 617.72 & 86 & 10.28 & 88 & 0.00 & 620.06 & 86 & 8.92 & 88 & 0.00 \\
\hline 0.06 & 523.30 & 84 & 10.34 & 89 & 0.00 & 496.20 & 100 & 11.01 & 103 & 0.00 & 498.36 & 100 & 9.65 & 103 & 0.00 \\
\hline $\begin{array}{l}\Delta \mathrm{x} \\
{[\mathrm{m}]}\end{array}$ & $\begin{array}{r}\mathrm{Q}_{\max } \\
{\left[\mathrm{m}^{3} \mathrm{~s}^{-1}\right]}\end{array}$ & $\begin{array}{r}\mathrm{i} \Delta \mathrm{t} \\
\left(\mathrm{Q}_{\max }\right)\end{array}$ & $\begin{array}{r}\mathrm{H}_{\max } \\
{[\mathrm{m}]}\end{array}$ & $\begin{array}{c}\mathrm{i} \Delta \mathrm{t} \\
\left(\mathrm{H}_{\max }\right)\end{array}$ & $\begin{array}{r}\text { Vol. err } \\
\%\end{array}$ & $\begin{array}{r}\mathrm{Q}_{\max } \\
{\left[\mathrm{m}^{3} \mathrm{~s}^{-1}\right]}\end{array}$ & $\begin{array}{r}\mathrm{i} \Delta \mathrm{t} \\
\left(\mathrm{Q}_{\max }\right)\end{array}$ & $\begin{array}{r}\mathrm{H}_{\max } \mathrm{r} \\
{[\mathrm{m}]}\end{array}$ & $\begin{array}{c}\mathrm{i} \Delta \mathrm{t} \\
\left(\mathrm{H}_{\max }\right)\end{array}$ & $\begin{array}{r}\text { Vol. err } \\
\%\end{array}$ & $\begin{array}{r}\mathrm{Q}_{\max } \\
{\left[\mathrm{m}^{3} \mathrm{~s}^{-1}\right]}\end{array}$ & $\begin{array}{r}\mathrm{i} \Delta \mathrm{t} \\
\left(\mathrm{Q}_{\max }\right)\end{array}$ & $\begin{array}{r}\mathrm{H}_{\max } \\
{[\mathrm{m}]}\end{array}$ & $\begin{array}{c}\mathrm{i} \Delta \mathrm{t} \\
\left(\mathrm{H}_{\max }\right)\end{array}$ & $\begin{array}{r}\text { Vol. err } \\
\%\end{array}$ \\
\hline 1000 & 686.96 & 73 & 8.69 & 76 & 0.00 & 655.83 & 82 & 9.99 & 84 & 0.00 & 658.15 & 82 & 8.64 & 84 & 0.00 \\
\hline 2000 & 687.00 & 73 & 8.69 & 76 & 0.00 & 655.86 & 82 & 10.00 & 84 & 0.00 & 658.18 & 82 & 8.64 & 84 & 0.00 \\
\hline 4000 & 687.07 & 73 & 8.70 & 75 & 0.00 & 655.95 & 82 & 10.01 & 84 & 0.00 & 658.27 & 82 & 8.65 & 84 & 0.00 \\
\hline 6000 & 693.34 & 72 & 8.77 & 74 & 0.00 & 662.70 & 80 & 10.05 & 82 & 0.00 & 664.95 & 80 & 8.70 & 82 & 0.00 \\
\hline 8000 & 693.42 & 72 & 8.77 & 74 & 0.00 & 662.94 & 80 & 10.06 & 81 & 0.00 & 665.18 & 80 & 8.70 & 81 & 0.00 \\
\hline $\begin{array}{l}\Delta \mathrm{t} \\
{[\mathrm{s}]}\end{array}$ & $\begin{array}{r}\mathrm{Q}_{\max } \\
{\left[\mathrm{m}^{3} \mathrm{~s}^{-1}\right]}\end{array}$ & $\begin{array}{r}\mathrm{i} \Delta \mathrm{t} \\
\left(\mathrm{Q}_{\max }\right)\end{array}$ & $\begin{array}{r}\mathrm{H}_{\max } \\
{[\mathrm{m}]}\end{array}$ & $\begin{array}{c}\mathrm{i} \Delta \mathrm{t} \\
\left(\mathrm{H}_{\max }\right)\end{array}$ & $\begin{array}{r}\text { Vol. err } \\
\%\end{array}$ & $\begin{array}{r}\mathrm{Q}_{\max } \\
{\left[\mathrm{m}^{3} \mathrm{~s}^{-1}\right]}\end{array}$ & $\begin{array}{r}\mathrm{i} \Delta \mathrm{t} \\
\left(\mathrm{Q}_{\max }\right)\end{array}$ & $\begin{array}{r}\mathrm{H}_{\max } \mathrm{r} \\
{[\mathrm{m}]}\end{array}$ & $\begin{array}{c}\mathrm{i} \Delta \mathrm{t} \\
\left(\mathrm{H}_{\max }\right)\end{array}$ & $\begin{array}{r}\text { Vol. err } \\
\%\end{array}$ & $\begin{array}{r}\mathrm{Q}_{\max } \\
{\left[\mathrm{m}^{3} \mathrm{~s}^{-1}\right]}\end{array}$ & $\begin{array}{r}\mathrm{i} \Delta \mathrm{t} \\
\left(\mathrm{Q}_{\max }\right)\end{array}$ & $\begin{array}{r}\mathrm{H}_{\max } \\
{[\mathrm{m}]}\end{array}$ & $\begin{array}{r}\mathrm{i} \Delta \mathrm{t} \\
\left(\mathrm{H}_{\max }\right)\end{array}$ & $\begin{array}{r}\text { Vol. err } \\
\%\end{array}$ \\
\hline 900 & 696.21 & 146 & 8.68 & 151 & 0.00 & 655.14 & 164 & 9.99 & 168 & 0.00 & 657.47 & 164 & 8.64 & 168 & 0.00 \\
\hline 1800 & 687.00 & 73 & 8.69 & 76 & 0.00 & 655.86 & 82 & 10.00 & 84 & 0.00 & 658.18 & 82 & 8.64 & 84 & 0.00 \\
\hline 3600 & 687.82 & 37 & 8.71 & 38 & 0.00 & 657.35 & 41 & 10.01 & 42 & 0.00 & 659.68 & 41 & 8.65 & 42 & 0.00 \\
\hline 5400 & 688.33 & 24 & 8.72 & 25 & 0.00 & 657.33 & 27 & 10.02 & 28 & 0.00 & 659.70 & 27 & 8.66 & 28 & 0.00 \\
\hline 7200 & 689.02 & 18 & 8.74 & 19 & 0.00 & 657.44 & 21 & 10.03 & 21 & 0.00 & 659.75 & 21 & 8.67 & 21 & 0.00 \\
\hline
\end{tabular}

wetted perimeter with respect to MIKE11, or (2) on the extension of the Cappelaere correction to non rectangular channels.

\section{Conclusions}

This paper deals with two inconsistencies deriving from the introduction, as proposed by Cunge (1969), of time variable parameters in the original Muskingum method. The first inconsistency relates to a mass balance error shown by the variable parameter MC method that can reach even values of 8 to $10 \%$. This incompatibility, has been widely reported in the literature and has been the objective of several tentative solutions, although a conclusive and convincing explanation has not been offered. In addition to the lack of mass balance, an even more important paradox is generated by the variable parameter MC approach, which apparently has never been reported in the literature. The paradox is: if one substitutes the parameters derived using Cunge approach back into the Muskingum equations, two different and inconsistent values for the water volume stored in the channel, are obtained.

This paper describes the analysis that was carried out, the explanation for the two inconsistencies and the corrections that have been found to be appropriate. A new Muskingum algorithm, allowing for variable parameters, has been derived, which leads to slightly different equations from the original Muskingum-Cunge ones. The quality of the results has been assessed by routing a test wave (the asymmetrical wave proposed by Tang et al. (1999) already adopted in the Flood Studies Report (FSR, NERC 1975)), through three channels with different cross sections (rectangular, triangular and trapezoidal), by varying the slope, the roughness, the space and time integration intervals. All the results obtained show that the new approach, in all cases, fully complies with the requirements of preserving mass balance, and at the same time satisfies the basic Muskingum equations. Finally, the effect of the pressure term inclusion as proposed by Cappelaere (1997) was also tested. The results show an additional improvement of the model dynamics when compared to the solutions using the full de Saint Venant equations, without any undesired effect on the mass balance and compliance with the Muskingum equations.

The new MCT approach can be implemented without necessitating substantial modifications in the MC algorithm and allows to correctly estimate both discharge and water stages. The MCT can be used as the basic routing component in many continuous soil moisture accounting hydrological 


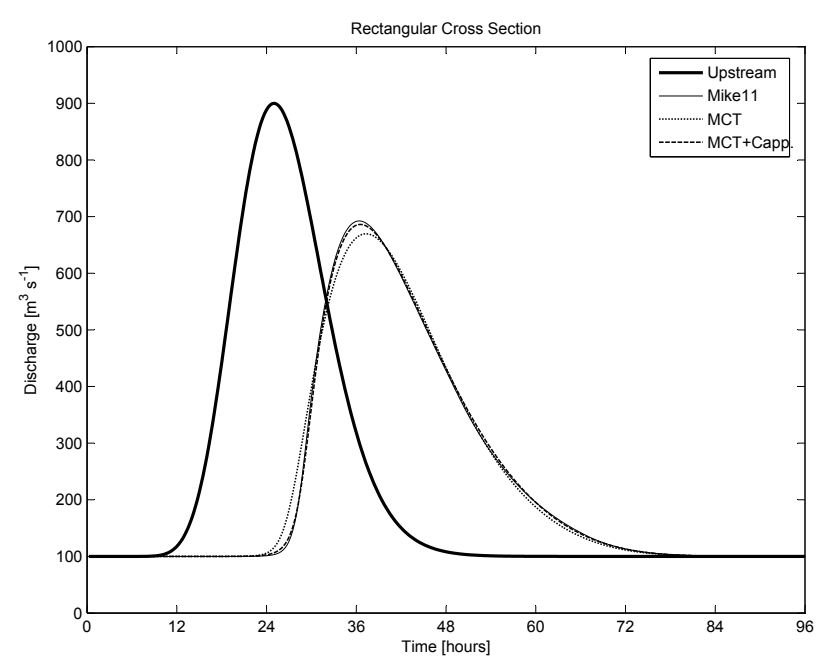

Fig. 8. Comparison, for the rectangular cross section, of the MIKE11 resulting discharges (thin solid line) with the ones obtained using the new MCT scheme (dotted line) and the new scheme with the Cappelaere (1997) correction (dashed line). The upstream inflow wave is shown as a thick solid line.

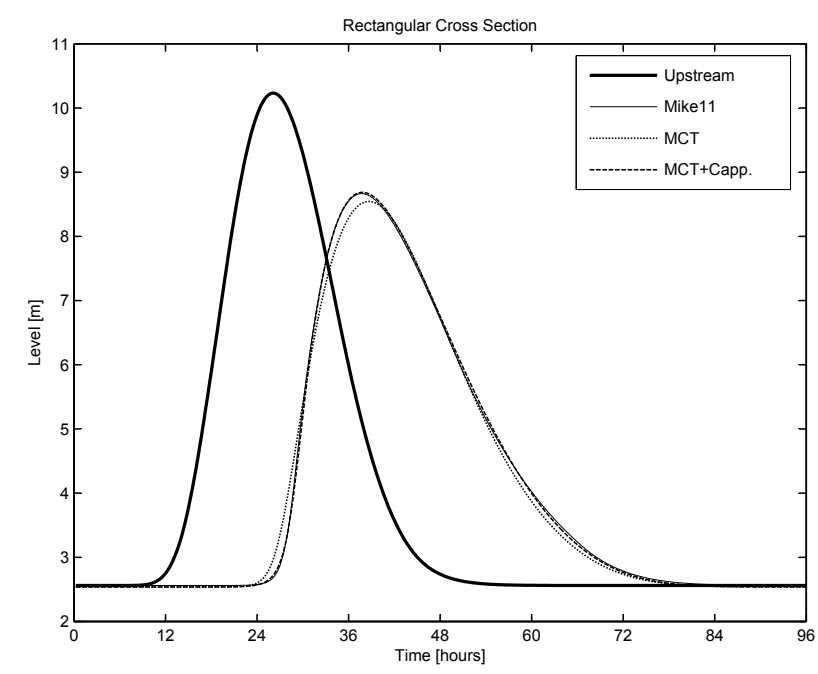

Fig. 9. Comparison, for the rectangular cross section, of the MIKE11 resulting water stages (thin solid line) with the ones obtained using the new MCT scheme (dotted line) and the new scheme with the Cappelaere (1997) correction (dashed line). The upstream inflow wave is shown as a thick solid line.

models, which require, particularly in the routing component, the preservation of water balance to avoid compensating it by adjusting other soil related parameter values. The proposed method will also be useful for routing flood waves in channels and in natural rivers with bottom slopes in the range of $10^{-3}-10^{-4}$ where the flood crest subsidence is one of the dominant phenomena. Within this range of slopes, the original MC approach was affected by the mass balance error which could be of the order of $10 \%$.



Fig. 10. Comparison, for the triangular cross section, of the MIKE11 resulting discharges (thin solid line) with the ones obtained using the new MCT scheme (dotted line) and the new scheme with the Cappelaere (1997) correction (dashed line). The upstream inflow wave is shown as a thick solid line.

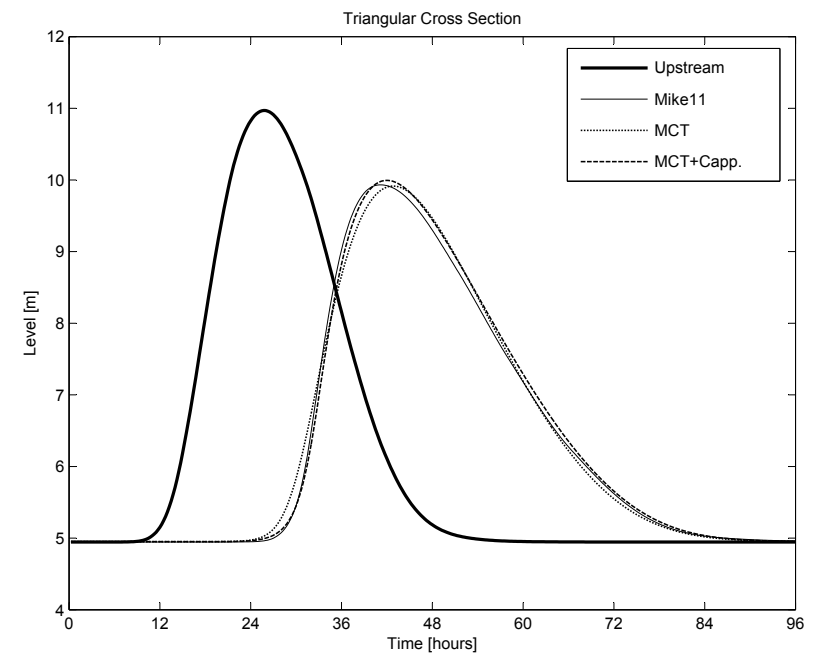

Fig. 11. Comparison, for the triangular cross section, of the MIKE11 resulting water stages (thin solid line) with the ones obtained using the new MCT scheme (dotted line) and the new scheme with the Cappelaere (1997) correction (dashed line). The upstream inflow wave is shown as a thick solid line.

Further research will aim at extending the MCT approach to more complex cross sections and at verifying whether the method could even more closely approximate the full de Saint Venant equations results by modifying the diffusivity through an additional correction of the friction slope, as proposed by Perumal and Ranga Raju (1998a, b) or following the Wang et al. (2006) approach. 


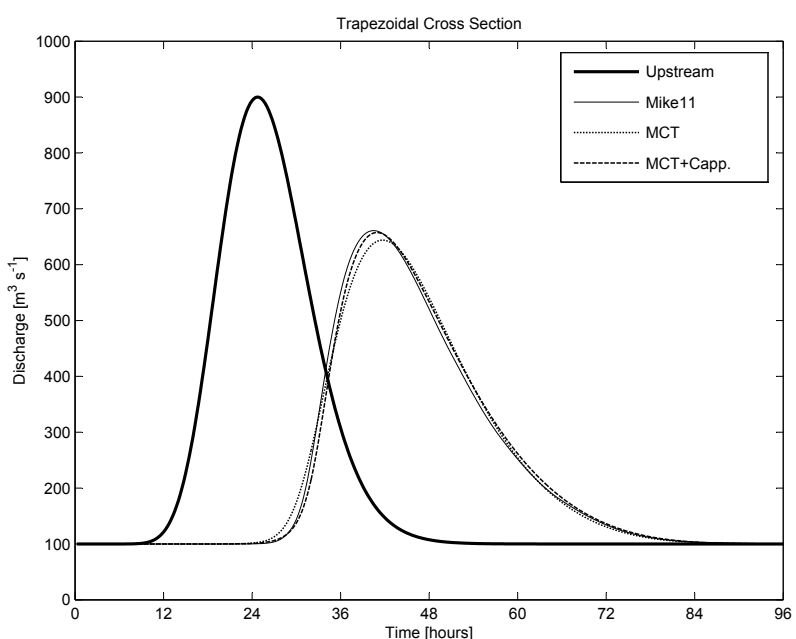

Fig. 12. Comparison, for the trapezoidal cross section, of the MIKE11 resulting discharges (thin solid line) with the ones obtained using the new MCT scheme (dotted line) and the new scheme with the Cappelaere (1997) correction (dashed line). The upstream inflow wave is shown as a thick solid line.

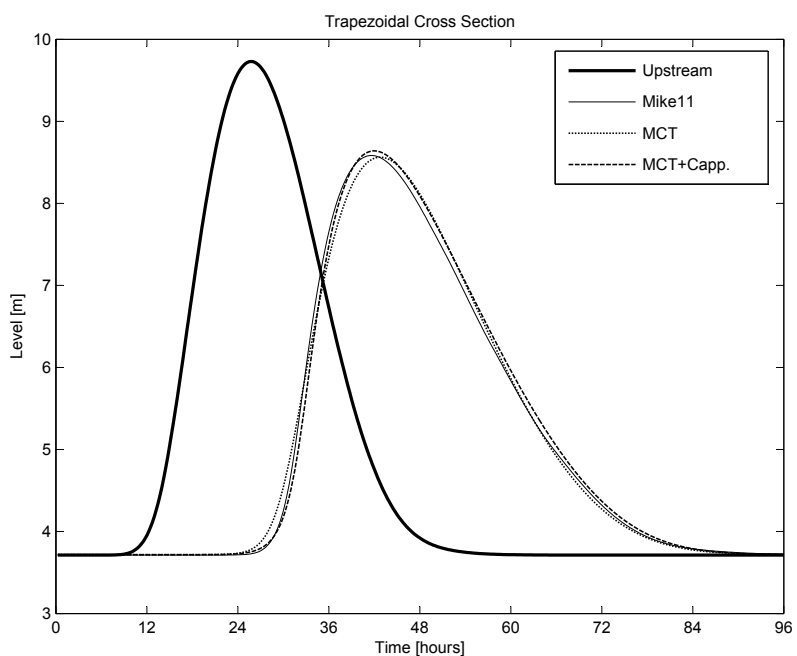

Fig. 13. Comparison, for the trapezoidal cross section, of the MIKE11 resulting water stages (thin solid line) with the ones obtained using the new MCT scheme (dotted line) and the new scheme with the Cappelaere (1997) correction (dashed line). The upstream inflow wave is shown as a thick solid line.

\section{Appendix A} Proof that $\frac{a_{t+\Delta t} b_{t+\Delta t}-a_{t} b_{t}}{\Delta t}$ is a consistent discretiza-
tion in time of $\frac{d(a b)}{d t}$

In Eq. (29) the following two derivatives $\frac{d[k \varepsilon I]}{d t}$ and $\frac{d[k(1-\varepsilon) O]}{d t}$ must be discretised in time. It is the scope of this appendix to demonstrate that their discretization leads to the expression used in Eqs. (29) and (30).

As can be noticed from Eqs. (10), the final Muskingum coefficients $C_{1}, C_{2}, C_{3}$, do not directly depend on $k$ and $\varepsilon$ taken singularly, but rather on the two products $k \varepsilon$ and $k(1-\varepsilon)$. Therefore, both derivatives can be considered as the derivatives in time of a product of two terms $a$ and $b$, being $a=k \varepsilon$ and $b=I$ in the first derivative and $a=k(1-\varepsilon)$ and $b=O$ in the second one.

Expanding the derivative $\frac{d(a b)}{d t}$ one obtains:

$\frac{d(a b)}{d t}=a \frac{d b}{d t}+b \frac{d a}{d t}$

which can be discretised in the time interval as follows:

$$
\begin{aligned}
\frac{\Delta(a b)}{\Delta t}= & {\left[\theta a_{t+\Delta t}+(1-\theta) a_{t}\right] \frac{b_{t+\Delta t}-b_{t}}{\Delta t} } \\
& +\left[\theta b_{t+\Delta t}+(1-\theta) b_{t}\right] \frac{a_{t+\Delta t}-a_{t}}{\Delta t}
\end{aligned}
$$

where $\theta$ is a non-negative weight falling in the range between 0 and 1 . Since the Muskingum method is derived on the basis of a centered finite difference approach in time, this implies that $\theta=\frac{1}{2}$.

Therefore, Eq. (A2), becomes

$$
\begin{aligned}
\frac{\Delta(a b)}{\Delta t} & =\frac{\left(a_{t+\Delta t}+a_{t}\right)}{2} \frac{b_{t+\Delta t}-b_{t}}{\Delta t}+\frac{\left(b_{t+\Delta t}+b_{t}\right)}{2} \frac{a_{t+\Delta t}-a_{t}}{\Delta t} \\
& =\frac{a_{t+\Delta t} b_{t+\Delta t}+a_{t} b_{t+\Delta t}-a_{t+\Delta t} b_{t}-a_{t} b_{t}}{2 \Delta t} \\
& +\frac{b_{t+\Delta t} a_{t+\Delta t}+b_{t} a_{t+\Delta t}-b_{t+\Delta t} a_{t}-b_{t} a_{t}}{2 \Delta t} \\
& =\frac{2 a_{t+\Delta t} b_{t+\Delta t}-2 b_{t} a_{t}}{2 \Delta t}=\frac{a_{t+\Delta t} b_{t+\Delta t}-a_{t} b_{t}}{\Delta t} \quad(\mathrm{~A} 3)
\end{aligned}
$$

Equation (A3) allows to write:

$$
\begin{aligned}
& \frac{\Delta[k \varepsilon I]}{\Delta t}=\frac{[k \varepsilon]_{t+\Delta t} I_{t+\Delta t}-[k \varepsilon]_{t} I_{t}}{\Delta t} \\
& \frac{\Delta[k(1-\varepsilon) O]}{\Delta t} \\
& =\frac{[k(1-\varepsilon)]_{t+\Delta t} O_{t+\Delta t}-[k(1-\varepsilon)]_{t} O_{t}}{\Delta t}
\end{aligned}
$$

as they appear in Eqs. (29) and are then used in the derivation of the MCT algorithm.

\section{Appendix B}

The Newton-Raphson algorithm to derive $y=y\left\{Q, n, S_{0}\right\}$ for a generic cross section

In general (apart from the wide rectangular cross section case), when in a channel reach the water stage $y[L]$ must be derived from a known discharge value $Q\left[L^{3} T^{-1}\right]$, a non-linear implicit problem must be solved. Since a direct 
closed solution is not generally available, several numerical approaches to find the zeroes of a non-linear function can be used, such as the bisection or the Newton-Raphson approaches.

In this case, given that the functions were continuous and differentiable (triangular, rectangular and trapezoidal cross sections), a simple Newton-Raphson algorithm was implemented. The problem is to find the zeroes of the following function of $y$ :

$$
f(y)=Q(y)-Q=0
$$

where $Q(y)\left[L^{3} T^{-1}\right]$ is defined as:

$$
Q(y)=\frac{\sqrt{S_{0}}}{n} \frac{A(y)^{5 / 3}}{P(y)^{2 / 3}}
$$

with $S_{0}$ [dimensionless] the bottom slope, $n\left[L^{1 / 3} T\right]$ the Manning friction coefficient, $A(y)\left[L^{2}\right]$ the wetted area and $P(y)[L]$ the wetted perimeter, as defined in Appendix C.

The Newton-Raphson algorithm, namely:

$y_{i+1}=y_{i}-f\left(y_{i}\right) / f^{\prime}\left(y_{i}\right)$

allows one to find the solution to the problem with a limited number of iterations starting from an initial guess $y_{0}$ and can be implemented in this case by defining:

$f\left(y_{i}\right)=Q\left(y_{i}\right)-Q=\frac{\sqrt{S_{0}}}{n} \frac{A\left(y_{i}\right)^{5 / 3}}{P\left(y_{i}\right)^{2 / 3}}-Q$

and

$f^{\prime}\left(y_{i}\right)=\left.\frac{d[Q(y)-Q]}{d y}\right|_{y=y_{i}}=\left.\frac{d Q(y)}{d y}\right|_{y=y_{i}}$

$=\frac{5}{3} \frac{\sqrt{S_{0}}}{n} \frac{A(y)^{2 / 3}}{P(y)^{2 / 3}}\left(B(y)-\frac{4}{5} \frac{A(y)}{P(y) s_{\alpha}}\right)=B(y) c(y)$

using the results given in Appendix $\mathrm{C}$.

\section{Appendix C}

The derivation of $A(h), B(h), c(h)$ and $\beta(h)$ for triangular, rectangular and trapezoidal cross sections

Given the cross-sections in Fig. 5, the following equations can be used to represent a generic triangular, rectangular or trapezoidal cross section.

$A(y)=\left(B_{0}+y c_{\alpha}\right) y$

the wetted area $\left[L^{2}\right]$

$B(y)=B_{0}+2 y c_{\alpha}$

the surface width $[L]$

$P(y)=B_{0}+2 y / s_{\alpha}$ the wetted perimeter $[L]$ with $B_{0}$ the bottom width $[L]$ ( $B_{0}=0$ for the triangular cross section) and $y$ the water stage $[L] ; c_{\alpha}=\cot (\alpha)$ and $s_{\alpha}=\sin (\alpha)$ are respectively the cotangent and the sine of the angle $\alpha$ formed by dykes over a horizontal plane (see Fig. 5) ( $c_{\alpha}=0$ and $s_{\alpha}=1$ for the rectangular cross section). Using these equations together with:

$Q(y)=\frac{\sqrt{S_{0}}}{n} \frac{A(y)^{5 / 3}}{P(y)^{2 / 3}}$

the discharge $\left[L^{3} T^{-1}\right]$

$v(y)=\frac{Q(y)}{A(y)}=\frac{\sqrt{S_{0}}}{n} \frac{A(y)^{2 / 3}}{P(y)^{2 / 3}}$

the velocity $\left[L T^{-1}\right]$ where $S_{0}$ [dimensionless] is the bottom slope and $n\left[L^{1 / 3} T\right]$ the Manning friction coefficient, the celerity is calculated as:

$$
\begin{aligned}
c(y) & =\frac{d Q(y)}{d A(y)}=\frac{1}{B(y)} \frac{d Q(y)}{d y} \\
= & \frac{5}{3} \frac{\sqrt{S_{0}}}{n} \frac{A(y)^{2 / 3}}{P(y)^{2 / 3}}\left(1-\frac{4}{5} \frac{A(y)}{B(y) P(y) s_{\alpha}}\right)
\end{aligned}
$$

the celerity $\left[L T^{-1}\right]$ and the correction factor to be used in the MCT algorithm is:

$\beta(y)=\frac{c(y)}{v(y)}=\frac{5}{3}\left(1-\frac{4}{5} \frac{A(y)}{B(y) P(y) s_{\alpha}}\right)$

the correction factor [dimensionless]

Edited by: E. Zehe

\section{References}

Bocquillon, C. and Moussa, R.: CMOD: Logiciel de choix de modèles d'ondes diffusantes et leur caractéristique, La Houille Blanche, 5(6), 433-437 (in French), 1988.

Cappelaere, B.: Accurate Diffusive Wave Routing, J. Hydraulic Eng., ASCE, 123(3),174-181, 1997.

Chow, V. T.: Handbook of Applied Hydrology, McGraw-Hill, New York, NY, 1964.

Chow, V. T., Maidment, D. R., and Mays, L. W.: Applied Hydrology, McGraw-Hill, New York, NY, 1988

Cunge, J. A.: On the subject of a flood propagation computation method (Muskingum method), Delft, The Netherlands, J. Hydr. Res., 7(2), 205-230, 1969.

Cunge, J.: Volume conservation in variable parameter MuskingumCunge method - Discussion, J. Hydraul. Eng., ASCE, 127(3), 239-239, 2001.

DHI Water and Environment: MIKE 11, User Guide and Reference Manual, DHI Water \& Environment, Horsholm, Denmark, 2000.

Dooge, J. C. I.: Linear Theory of Hydrologic Systems, USDA Tech. Bull. 1468. US Department of Agriculture, Washington, D.C., 1973.

Hayami S.: On the propagation of flood waves, Bulletin n. 1, Disaster Prevention Research Institute, Kyoto University, Japa, 1951n. 
Kalinin, G. P. and Miljukov, P. I.: Approximate methods for computing unsteady flow movement of water masses. Transactions, Central Forecasting Institute. Issue 66 (in Russian, 1958).

Koussis, A. D.: Comparison of Muskingum method difference scheme Journal of Hydraulic Division, ASCE, 106(5), 925-929, 1980.

Koussis, A. D.: Accuracy criteria in diffusion routing: a discussion. Journal of Hydraulic Division, ASCE, 109(5), 803-806, 1983.

Liu Z. and Todini E.: Towards a comprehensive physically based rainfall-runoff model, Hydrol. Earth Syst. Sci., 6(5), 859-881, 2002.

Liu, Z. and Todini, E.: Assessing the TOPKAPI non-linear reservoir cascade approximation by means of a characteristic lines solution, Hydrol. Processes, 19(10), 1983-2006, 2004.

McCarthy, G. T.: The Unit Hydrograph and Flood Routing. Unpublished manuscript presented at a conference of the North Atlantic Division, U.S. Army, Corps of Engineers, June 24, 1938.

McCarthy, G. T.: Flood Routing, Chap. V of "Flood Control", The Engineer School, Fort Belvoir, Virginia, pp. 127-177, 1940.

Nash, J. E.: The form of the instantaneous unit hydrograph. IUGG General Assembly of Toronto, Vol. III - IAHS Publ., 45, 114$121,1958$.

Patankar, S. V.: Numerical heat transfer and fluid flow. Hemisphere Publishing Corporation, New York, pp. 197, 1980.

Perumal, M. and Ranga Raju, K. G.: Variable Parameter StageHydrograph Routing Method. I: Theory. Journal of Hydrologic Engineering, ASCE, 3(2), 109-114, 1998a.

Perumal, M. and Ranga Raju, K. G.: Variable Parameter StageHydrograph Routing Method. I: Theory, J. Hydrol. Eng., ASCE, 3(2), 115-121, 1998b.

Perumal, M., O'Connell, P. E., and Ranga Raju, K. G.: Field Applications of a Variable-Parameter Muskingum Method, J. Hydrol. Eng., ASCE, 6(3), 196-207, 2001
Ponce, V. M. and Chaganti, P. V.: Variable-parameter MuskingumCunge revisited, J. Hydrol., 162(3-4), 433-439, 1994.

Ponce, V. M. and Lugo, A.: Modeling looped ratings in Muskingum-Cunge routing, J. Hydrol. Eng., ASCE, 6(2), 119124, 2001.

Ponce, V. M. and Yevjevich, V.: Muskingum-Cunge method with variable parameters, J. Hydraulic Division, ASCE, 104(12), 1663-1667, 1978.

Price, R. K.: Variable parameter diffusion method for flood routing. Rep. N.INT. 115, Hydr. Res. Station, Wallingford. UK, 1973.

Stelling, G. S. and Duinmeijer, S. P. A.: A staggered conservative scheme for every Froude number in rapidly varied shallow water flows, Int. J. Numer. Meth. Fluids, 43, 1329-1354, 2003.

Stelling, G. S and Verwey, A.: Numerical Flood Simulation, in Encyclopedia of Hydrological Sciences, John Wiley \& Sons Ltd, 2005.

Szél S. and Gáspár C.: On the negative weighting factors in Muskingum-Cunge scheme, J. Hydraulic Res., 38(4), 299-306, 2000.

Tang, X., Knight, D. W. and Samuels, P. G.: Volume conservation in Variable Parameter Muskingum-Cunge Method, J. Hydraulic Eng. (ASCE), 125(6), 610-620, 1999.

Tang, X. and Samuels, P. G.: Variable Parameter MuskingumCunge Method for flood routing in a compound channel, J. Hydraulic Res., 37, 591-614, 1999.

Todini E. and Bossi A.: PAB (Parabolic and Backwater) an unconditionally stable flood routing scheme particularly suited for real time forecasting and control, J. Hydraulic Res., 24(5), 405-424, 1986.

U.S. Army Corps of Engineers: HEC-RAS Users Manual. http://www.hec.usace.army.mil/software/hec-ras/documents/ userman/index.html, 2005

Wang, G. T., Yao Ch., Okoren C., and Chen S.: 4-Point FDF of Muskingum method based on the complete St Venant equations, J. Hydrol., 324, 339-349, 2006. 